\title{
Population Growth and Environment as a Self-organizing System
}

\author{
PETER M. ALLEN \\ International Ecotechnology Research Centre, Cranfield University, Bedford, MK43 OAL, UK
}

(Received 16 November 1998)

Over recent years a new understanding of complex systems, and their dynamics and evolution has emerged, and these have been shown to provide a new basis for models of the changing patterns of population and economic activities that shape the landscape. In this paper we make clear the necessarily partial description that any particular model must provide, and show the importance of a multidisciplinary, holistic understanding, linking any particular model to the co-evolution of its environment. In addition, we show how evolutionary processes link the microscopic level of molecules through successive scales of structure and organization ultimately to the biosphere itself, to issues of climatic change, of biomes at the continental scale and atmospheric and oceanic circulation patterns. Some very recent results will be shown which demonstrate that the world climate has already been modified considerably by human activities, particularly agriculture, underlining the vital need to understand better the on-going interaction between human activities and the biosphere.

Models will be described which can link the co-evolution of these multiple scales of organization and change, and which can be used to help to explore the consequences of different possible policies, and in this way to provide information concerning the agendas, risks and issues to be addressed in the 21 st Century, as well as pointing to possible policies that may be appropriate. Already models exist which can explore the dynamics of urban development, the patterns of land-use, and the possible environmental impacts of these in the context of a still fast growing population. Such models provide a framework within which questions such as those concerning energy consumption, transportation, social conditions can be explored and agendas and priorities set. Clearly, advances in information and telecommunications technologies present great opportunities for increasing accessibilities without necessarily increasing mobility or energy consumption, and models which can help in assessing their potential impact on development and in their successful implementation are of great value.

Complex system models can also be of great use in exploring the long term implications of the present, increasing, reliance on market systems and economic signals in the allocation of resources and patterns of investment. In particular, complex systems models can explore the effects of the precise regulatory framework within which a market operates, and as a result may be able to suggest ways in which long term, sustainable development can be achieved despite the present short term horizons of the players in market dynamics. In addition, of course, they can illuminate and inform actors about the longer term, and perhaps actually lengthen the time horizon considered by market participants. In short, the insights arising from complex systems models could, hopefully, play a role in expanding the understanding, the conceptual framework and the ethical basis of decision making in the 21 st Century. 
Keywords: Complex systems, Evolution, Urban self-organization, Integrated models, Decision support tools

\section{INTRODUCTION}

With the new millenium approaching, reflection on the human predicament and its possible future seems appropriate. The "enlightenment", and its expression in the industrial revolution gave people the hope of a better future for all, where the quality of life would continually increase, for ever more people, under the benign influence of scientific and technological progress. It projected the triumph of rationality, and reason over the dark forces of superstition and ignorance, and seemed to promise wealth and health for all. Today, however, uncertainties and doubts concerning our future are apparent everywhere. Our present way of life, heavily dependent on material and energy inputs, seems unsustainable over the long term, and naturally this gives rise to some vital questions. How can the unsustainable desired lifestyles of the modern world be changed in order to make them sustainable? Should we change our desires, or change the means by which those desires are realized? And, what is sustainability anyway? Is it some maximal level of production and consumption corresponding to the greatest possible exploitation of "natural" resources in what would largely be an "artificial" environment, or does it concern our capacity to adapt and change and "fit" within a relatively "natural" environment, and to develop a diverse and varied abundance of activities, spreading the "environmental load" of our activities broadly, and using our creativity and innovation to better fit into nature?

The problems with which we are faced result from the success of the traditional scientific view of the world as a mechanical system, whose workings could be completely understood, and therefore which could be ever-increasingly exploited. The traditional "engineering" approach to a problem or a constraint has always been to specify exactly its apparent "role" and context, and view everything as a "device" which turns inputs into outputs at a certain "cost". Progress then was made by producing a piece of technology, a mechanism or structure, which could "better" turn the inputs into outputs according to the established "cost/benefit" criteria. But the very success and growth of these technological solutions changes the context in which they exist: both from the input side - the raw materials and production structures that are required, and the output side, meaning the impacts on society and on the biosphere.

The institutional structures of society, particularly with their present heavy emphasis on economic variables, and the very general motivation of short term profit mean that the failure to foresee the limits of technology, and the growth of environmental and social problems was almost inevitable. This myopia stems from the traditional philosophy of science, rooted in Newtonian concepts, that saw reductionism as the key to understanding. In this reductionist view, improving (according to local criteria) the "separate pieces" of something must make the whole perform better. But, as we shall see, we really inhabit a Complex System in which each part, and indeed different levels of structure and organization are coupled together and co-evolve, so that the pieces of something cannot be considered separately from the whole. The new millenium is therefore a good time to recognize that we need to develop a new approach to the human situation, one based on our understanding of Complex Systems, and the limits to prediction and understanding that this implies. We need to see ourselves as inhabiting a nested set of co-evolved, hierarchical structures, linking through intermediate levels of organization, the biosphere to the atoms and molecules at a particular place. In reality, the climate, the ocean currents, the landscapes, the settlement patterns, the cities and each individual are all linked, in a complex web of interaction, some apparently stable and some evolving. In the new century we can 
hope to understand our predicament a little better, defining our agendas at least, and possibly gaining some wisdom in our decision making.

\section{EVOLUTION AND MECHANICS}

If we examine a region, and consider the remains of populations and artefacts that litter the landscape, then after dating and classifying them, an evolutionary tree of some kind emerges, possibly with discontinuities suggesting disaster and invasion, but nevertheless suggesting a changing "cast of characters" and of behaviours, over time.

On the left, we have "reality". It is drawn as a cloud, since we can say little about it other than that it includes all detail of everything, everywhere, as well as all perceptions and all points of view. However, if we simply list what we see then it includes a landscape with people of many kinds performing a variety of tasks, businesses, factories, homes, vehicles, and also fossils, disused mines and factories, closed railways, buried cities and evidence of much that has disappeared. By constructing a series of taxonomic rules concerning the differences and similarities of the objects, together with their dates, we can construct an "evolutionary tree", showing that species, behaviours, forms, or artefacts emerged and evolved over time.

This is really subjective however, since the differences that we choose to recognize reflect already our particular vision of what is "important" in a social and economic system. The rules of classification that we use are seldom explicitly justified however, and often result from previous experience about such systems and what seems to matter in them. Are there socio-economic "types" and if so, what are they? Do demographic characteristics reflect economic categories? Do firms of the same sector and size behave similarly? What is a sector? Is there as much variation within a group as between groups? Whatever the precise arguments advanced, in order to "understand" a situation, and its possible outcomes, we do classify the system into components, and attempt to build mathematical models that capture the processes that are increasing or decreasing these different components.

At any particular moment therefore, we identify the different objects or organisms that are present, and attempt to write down some "population dynamics" describing the increase and decrease of each type. We apply the traditional approach of physics, which is to identify the components of a system, and the interactions operating on these, both to and from the outside world and between the different populations of the system. In ecology, this will consist of birth and death processes, where populations give birth at an average rate if there is enough food, and eat each other according to the average rates of encounter, capture and digestion. In economics, the macroscopic behaviour of the economy is assumed to result from the aggregate effects of producers attempting to maximize their profits, and of customers attempting to maximize their utility. This assumes that they know the outcome of what they have not yet tried and also that transactions, production, and consumption occur at average rates, changing the GNP, unemployment and other macroscopic indicators. These ideas are all based on the "mechanical paradigm" of Newtonian physics, and assume that all individuals, producers, and consumers of a given type are taken to be identical and equal to the average type. Such a model expresses the behaviour or functioning of the system at that time as a result of the causal relationships that are present. This gives the illusion that we have a mechanical representation of the system which can be run on a computer, to give predictions.

However, as we see clearly from our broader picture of Fig. 1 which shows the "evolutionary tree", the predictions that such a model can give can only be correct for as long as the taxonomy of the system remains unchanged. The mechanical model of deterministic equations that we can construct at any given time has no way of producing "new" types of objects, new variables, and so the "predictions" that it generates will only be true until some moment, unpredictable within the model, when there is an adaptation or innovation, and new behaviour emerges. 


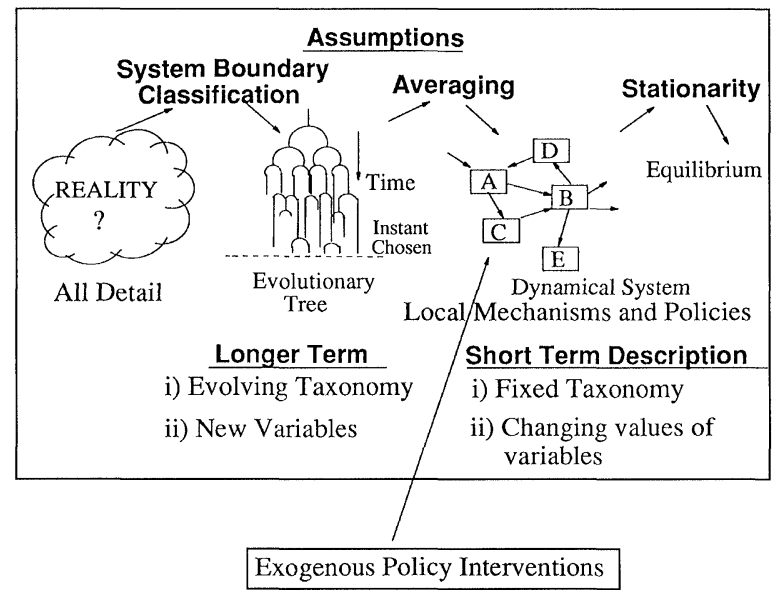

FIGURE 1 Data and classification of populations and artefacts lead to the picture of an evolutionary tree of some kind. Mathematical models have concentrated on the causal relations at a given time.

In order to build mathematical models, we identify the different objects or organisms that are present at a particular moment and attempt to write down the mechanisms describing the increase and decrease of each type. We apply the traditional approach of physics, which is to identify the components of a system, and the interactions operating on these, both to and from the outside world and between the different populations of the system. By considering the demographic, economic and environmental processes in play at a given time, a mathematical model can be produced which appears to offer deterministic predictions concerning the future, assuming different possible policies or exogenous events.

However, as we see clearly from our broader picture of the "evolutionary tree", the predictions that such a model can give can only be correct for $a s$ long as the qualitative structure of the system remains unchanged. Development concerns particularly the emergence of new spatial organization, new activities and behaviours, and the structural changes that these lead to. The mechanical model of deterministic equations that we can construct at any given time has no way of producing "new" types of objects, new variables, and so the "predictions" that it generates will only be true until some moment, unpredictable within the model, when there is an adaptation or innovation, and new behaviour emerges.

In recent research new models have been developed (Allen, 1992a,b; 1993; 1994a,b) which can generate a true structurally changing evolution, with new entities and activities appearing. However, the relationship of these models to more conventional ones has not been made clear, and this is the aim of this first section. The conceptual framework of Fig. 1 allows us to understand the relationship between different modelling techniques used to provide decision support, in terms of the assumptions that underlie them. We compare the assumptions made by different approaches to policy exploration and planning, such as static optimization models, evaluations based on short term cost/benefits, and the difficulties involved in long term, complex simulations.

Clearly, the evolutionary tree reflects the changing structure of the system, with different variables, over the long term, as different types of actors emerge, flourish and then dissappear or change. In the short term, however, we can identify the different objects or actors that are present, and write down some "system dynamics equations" describing the mutual interaction of the different actors present. In other words, in describing the short term we can apply the traditional approach of physics (Prigogine and Stengers, 1987; Allen, 1988), which is to identify the components of a system, and the interactions operating on these, both to and from the outside world and between the different populations of the system. In ecology, this will consist of birth and death processes, where populations give birth at an average rate if there is enough food, and eat each other according to the average rates of encounter, capture and digestion. In economics, the macroscopic behaviour of the economy is assumed to result from the aggregate effects of producers attempting to maximize their profits, and of customers attempting to maximize their utility. Such a model expresses the behaviour or functioning of the system, given its structure, but does not "explain" 
why this structure is there. In order to do this, we must try to understand and "model" the evolutionary tree of successive structures.

Let us consider carefully the assumptions that have to be made in order to arrive at a description in terms of system dynamic equations. Such systems are characterized by dynamical equations of the type:

$$
\begin{aligned}
& \frac{\mathrm{d} x}{\mathrm{~d} t}=G(x, y, z, \ldots), \\
& \frac{\mathrm{d} y}{\mathrm{~d} t}=H(x, y, z, \ldots), \\
& \frac{\mathrm{d} z}{\mathrm{~d} t}=J(x, y, z, \ldots),
\end{aligned}
$$

where $G, H$, and $J$ are functions which have nonlinear terms in them, leading to changes in $x, y$ and $z$ which are not simply proportional to their size. Also, these functions are made up of terms which involve variables $x, y$ and $z$ and also parameters expressing the functional dependence on these. These parameters reflect three fundamentally different factors in the working of the system:

- The values of external factors, which are not modelled as variables in the system. These reflect the "environment" of the system, and of course may be dependent on spatial coordinates. Temperature, climate, soils, world prices, interest rates are possible examples of such factors.

- The effects of spatial arrangement, of juxtaposition, of the entities underlying the system. Often these will express non-linear effects of density for example.

- The values corresponding to the "performance" of the entities underlying $x, y$ or $z$, due to their internal characteristics like technology, level of knowledge or particular strategies.

These three entirely different aspects have not been separated out in much of the previous work concerning non-linear systems, and this has led to much confusion. Equations of the type shown above display a rich spectrum of possible behaviours in different regions of both parameter space and initial conditions. They range from a simple approach to a homogeneous steady state, characterized by a point attractor, through that of sustained oscillation of a cyclic attractor, to the well known chaotic behaviour characteristic of a strange attractor. These can either be homogeneous, but, much more importantly, they can involve spatial structure as well, and the phenomena of self-organization can be seen as the adaptive response of a system to changing external conditions, even if it is viewed as having fixed attributes for its microscopic entities. In other words, we shall see that self-organization is a collective, spatial response to changing conditions rather than an evolutionary response on the part of its constituent individuals.

In order to see this let us first consider the assumptions that are made in deriving system dynamics equation such as in (1). In the complex systems that underlie something like the "economy", there is a fundamental level which involves individuals and discrete events, like making a widget, buying a washing machine, driving to work, etc. However, instead of attempting to "model" all these details, these are treated in an average way, and as has been shown elsewhere (Allen, 1990), in order to derive deterministic, mechanical equations to describe the dynamics of a system, two assumptions are required:

- events occur at their average rate (Assumption 1),

- all individuals of a given type, $x$ say, are identical and of average type (Assumption 2).

The errors introduced by the first assumption can be corrected by using a deeper, probabilistic dynamics, called the "Master Equation" (Weidlich and Haag, 1983), which while retaining Assumption 2 assumes that events of different probabilities can and do occur. So, sequences of events which correspond to successive runs of good or bad "luck" are included, with their relevant probabilities. As has been shown elsewhere (Allen, 1988) for systems with non-linear interactions between individuals, what this does is to destroy the idea of a trajectory, and gives to the system a collective adaptive capacity corresponding to the spontaneous spatial 
reorganization of its structure. Without going to the mathematical rigour of the Master Equation, its effects can be imitated to some degree by simply adding "noise" to the variables of the system, so that the noise can search out different spatial arrangements which may be stable under the new conditions. In other words, self-organization can be seen as the adaptive response to changing external conditions, and may be greatly enhanced by adding noise to the deterministic equations of system dynamics.

The fact is that unpredictable runs of good and bad luck, represented by "noise", can occur, and this means that the precise trajectory of the system does not exist in the future. Also, the fact of these deviations from the average rate of events means that a real system can "tunnel" through apparently impassable potential barriers, the separatrices in state space, and can switch between attractor basins and explore the global space of the dynamical system in a way that the dynamical system would not itself predict.

Let us now make the distinction between selforganization and evolution. Here, it is the Assumption 2 that matters, namely that all individuals are identical and equal to the average type. The real world is characterized by system in which there is in fact microscopic diversity underlying the classification scheme of variables chosen at any particular time for the system model. The effects of this have been described elswhere (Allen and McGlade, 1987; Allen, 1988; 1990; 1992a,b; 1994a,b) and so we shall simply say that when microscopic diversity is taken into account, then it leads to a mathematical model of an evolutionary tree, where new behaviours emerge and an ecology of actors eventually fills any resource space. We shall not discuss these wider issues any further here.

We can summarize the different levels of model from deterministic equations to full evolutionary models as shown in Fig. 2.

In reality, the interaction of the system within the larger one which is its environment will lead to a coevolutionary dialogue involving the wider situation. This Co-evolution of system and environment means that, in reality, the changes in the environmental parameters will partially be related to the adaptations that occur within the system.

Systems models in general describe the connected behaviour of sub-systems. If these are few, and each sub-system has a fixed internal structure, then a

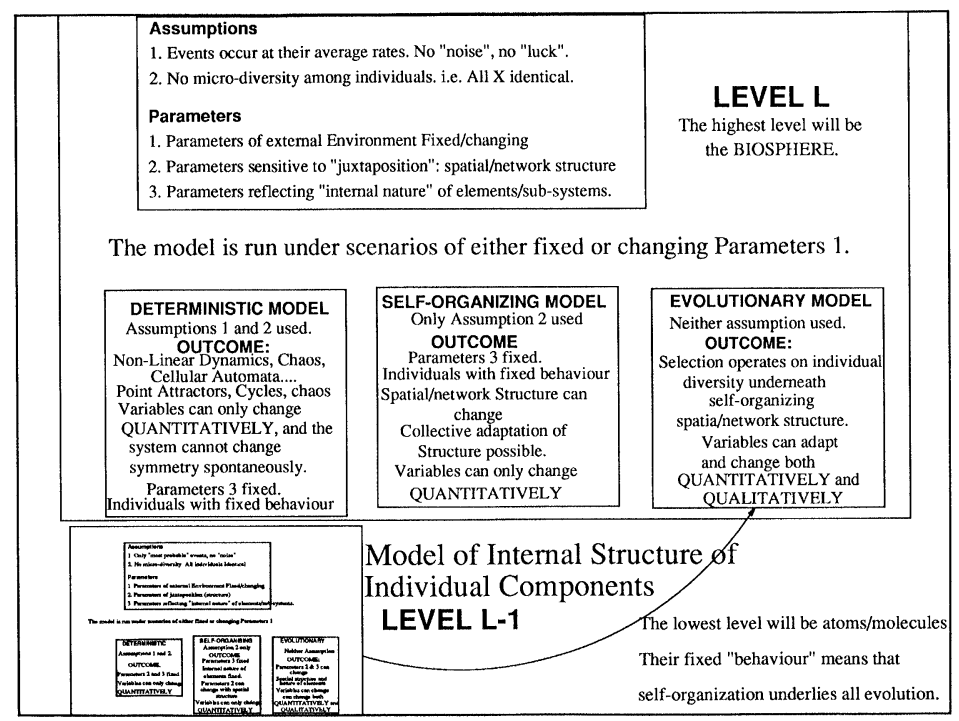

FIGURE 2 The hierarchy of modelling. Deterministic and self-organizing models assume that the underlying sub-systems are "fixed" in nature, while an evolutionary model attempts to deal with possible changes at that level as well. 
systems model can be a complete representation of the behaviour of the connected parts. A gear box, for example, can be modelled successfully as an assembly of gears, providing that none of the gear wheels gets stressed beyond breaking point. A complex system, however, is one where there are so many subsystems connected together, that some reduced, aggregate description is necessary. In this case the behaviour will be defined in terms of aggregate "variables", representing "average" types and average events. Obviously, all macroscopic systems are "complex" systems, since they are ultimately composed of atoms and molecules. However, if, as in the case of the gearbox, there exist macroscopic components whose internal structure can be assumed to be fixed during the system run, then a simple systems model will correctly describe the course of events, providing that the integrity of the components is not compromised. Clearly, for cases of breakage, a deeper description may be needed. For complex systems made up of microcomponents with fixed internal structure, their interactions can lead to selforganization. However, if the microcomponents have internal structure, and if in addition this can change through time, thus changing the behaviour of the individual elements, then evolution can take place as the emergent macrostructure affects the local circumstances experiences by individuals, and this in turn leads to a structured adaptive response which in turn changes the macrostructure generated.

Clearly, "dissipative structures", as discovered and investigated by the Brussels School (Nicolis and Prigogine, 1977; Prigogine and Stengers, 1987; Shieve and Allen, 1982) are all examples of selforganization, since the molecules underlying the chemical and biological reactions studied do not change their nature. Complex spatio-temporal organization can form in such systems, as a result of the non-linearities of the interaction processes, and so they demonstrate the emergence of structure at a higher scale than that of the interacting entities. In the case of the Brusselator, for example, the molecules interact over distances of $10^{-8} \mathrm{~cm}$, but the spiral waves and characteristic patterns are of the order of centimetres.
Complex systems modelling involving elements with internal structure that can change however, leads naturally to a hierarchy of linked levels of description. Stability, or at least metastability is achieved when the microstructures are compatible with the macrostructures they both create and inhabit.

In many cases in addition to the Assumptions 1 and 2 required to yield deterministic, dynamic equations, a further assumption is introduced that the system is also supposed to have run itself to equilibrium, so that the correspondence between the real object and that model is made through equilibrium relations of balance between the variables. In neo-classical economics, much of spatial geography, and many models of transportation and land-use, the models that are used operationally today are still based on equilibrium assumptions. Locations of jobs and residences, land values, traffic flows, etc. are all assumed to reach their equilibrium configurations "rapidiy", following some policy or planning action, with the more extreme practitioners even using the theory of "rational expectations" to claim that people "knew" what the equilibrium would be before it happened and so could and did prepare to move to it.

Such an approach, as well as being somewhat absurd, falls to take into account the possibility of any "run-away" processes where growth encourages growth, decline leads to further decline and so on, which can occur during a change. Actions directly affect which evolutionary trajectory the system takes, an evolutionary trajectory that does not stop after any particular delay. Similarly, the equilibrium approach supposes that the situation observed in a region or market system expresses some maximized utility for the actors, where consumers and producers have minimized costs and maximized benefits. This approach assumes that all the actors know what they want, know how to get it, and if observed, are doing what they would wish - given the choices open to them. Such ideas gave rise in reality to a purely descriptive approach to problems, following, in a kind of post hoc calibration process, the changes that occurred. 
It leads to a "laisser faire" strategy, unjustifiably restricting the options open to actors and decision makers with multiple and complex agendas.

In fact, those wishing to use equilibrium methods should accept the burden of proof, since it is they who make the additional assumption. They should prove that the relaxation times of the processes involved in the system are truly short with respect to any time of interest, and therefore that their assumption is justified. In reality, in the main stream of economics, such evidence is never presented, but nevertheless, non-equilibrium methods have until recently in general simply been ignored. This is really because accademic disciplines are also the product of social phenomena, and the "positive feedback" processes of mutual citation and felicitation. "Lock in" is not just a phenomenon seen in technology change. It runs very deeply through all self-organizing systems.

However, although dynamic models trace trajectories in time, they cannot anticipate the qualitative changes that may occur when an evolutionary step takes place. At such a time, the taxonomy of the system changes, and therefore the mathematical model of causal relations ceases to be correct. It might be good for some time, while the taxonomy is stable and no new classes or types have appeared. But, this will only be revealed when the model is shown to be incorrect, and in need of re-formulation. In Physics and Chemistry the predictive models which work so well rely on the fact that the individual elements that make up the system must obey fixed laws which govern their behaviour. The mechanisms are fixed, and the molecules never learn.

But, living systems cannot be described by such deterministic laws. To see why, let us imagine a very simple human situation, for example, of traffic moving along a highway or of pedestrians milling around a shopping centre. Clearly, movements cannot be predicted using Newton's laws of motion because acceleration, change of direction, braking and stopping occur at the whim of each driver or pedestrian. Newton's laws, the laws of physics are obeyed at all times by each part of the system, but, despite this, they are not of help in predicting what will happen because the decision to coast, turn, accelerate or brake lies with the human being. Planets, billiard balls, and point particles are helpless slaves to the force fields in which they move, but people are not! People can switch sources of energy on or off and can respond, react, learn and change according to their individual experience and personality. They can see the potential usefulness for some modification in their timing, technique or tools, and they can tinker and experiment perhaps to find ways to overcome a problem, or a new way to achieve some desired result. This is where innovation comes from, and so, the diversity of the experiments performed or ideas tried out will reflect the diversity of the people concerned, and the ability of these experiments to be translated into improved and new production and business will reflect the encouragement or discouragement experienced by innovative individuals, and the information flows and scanning that organizations are doing to gather and evaluate such initiatives.

Because of this uncertainty in the longer term, we cannot know what actions are best now. Even if an individual knows exactly what he would like to achieve, then because he cannot know with certainty how everyone else will respond, he can never calculate exactly what the outcome will be. He must make his decision, and see what happens, being ready to take corrective actions, if necessary. Since, in business, on the road and in the shopping centre we are all making these kinds of decisions, simultaneously, all the time, it is not surprising that occasionally there are accidents, or that such systems run in a "non-mechanical" way. An important point to remember here is of course that human beings have evolved within such a system and therefore that the capacity to live with such permanent uncertainty is quite natural to us. It may even be what characterizes the living. However, it also implies that much of what we do may be inexplicable in rational terms.

The "mechanical" approach is softened but not fundamentally changed by statistical models of decision processes where the probability of making 
a particular choice is proportional to the expected utility derived. This gives rise to probabilistic behaviour for individuals and deterministic behaviour for sufficiently large populations. However, this simple approach ignores the fact that decisions made by individuals are not really independent of each other, and that there is an effect of the communication between individuals. Fashions, styles and risk minimizing strategies affect collective behaviour considerably, and mean that it cannot be derived as the sum of independent, individual responses.

\section{EVOLUTIONARY DRIVE}

As we have seen above, in deriving kinetic equations in order to model the system that exists at a given time, it has been necessary to derive a reduced description of reality. This is made in terms of typical elements of the system, stereotypes, according to the classification scheme that we have decided to apply. Underneath the "model" there will always be the greater particularity and diversity of reality.

In the mechanical view, predictions can be made by simply running the equations forward in time, and studying where they lead. Is there a unique "attractor", into which all initial states eventually fall, or are there many possible final end points? Does the system continue in a series of eternal cycles? Or, does it display chaotic behaviour, as the trajectory wraps itself around a "strange attractor"? Despite the interest of these questions, we should remember they are only of any significance if the equations and the fixed mechanisms within them remain a good description of the system, and explanation can be obtained in terms of the internal functioning of the system. But, from the picture of the evolutionary tree in Fig. 1 that we know really characterizes complex systems, the taxonomy of the system, the variables present and the mechanisms which link them actually change over time. Because of this, the dynamical system that we are running as a model of the system will only be a good description for as long as there is no evolutionary change, and no new variables or mechanisms appear. In other words, the predictions of the dynamical system model will only be correct for as long as the model itself is a correct description of the system, and this is only for some unpredictable length of time.

Figure 1 offers us a conceptual framework within which we can understand technological evolution, and this has been described elsewhere (Allen, 1994a,b). In order to describe evolutionary change, we must try to suppress Assumption 2 discussed above and put back the effects of innovators. Nelson and Winter (1982) have set out a seminal framework for economics in which internal variabilities and the differential survival of firms are explicitly taken into account as they compete in the production of a particular good. The evolution concerns returns on investment and techniques of production, and has been the basis for many later studies (Anderson et al., 1988; Silverberg et al., 1988; Saviotti and Metcalfe, 1991). Clark and Juma (1987) have also set out the essential points concerning the difference between the long and short term view of economic systems, and how this leads to an evolutionary view.

Returning to the general conceptual framework of Fig. 1, we see that in order for us to understand and model a system that can change its taxonomy endogenously we must "put back" what Assumptions 1 and 2 took out in order to get to the deterministic description of non-linear dynamics. Clearly, the future of any system will be due to two kinds of terms: changes brought about by the deterministic action of the typical behaviour of its average components, and structural qualitative changes brought about by the presence of nonaverage components and conditions within the system.

We really have a dialogue between the "average dynamics" of the chosen description (a process that results in what we may call selection) and the exploratory, unpredictable "non-average" perturbations around this that results from the inevitable occurrence of non-average events and components, 
a search or exploration process that generates information about the "pay offs" for other behaviours. This leads to the new concept of Evolutionary Drive (Allen and McGlade, 1987; Allen and Lesser, 1993).

In order to explore the behaviour of systems with endogenously generated innovations and selection we define a "possibility space", a space representing the range of different techniques and behaviours that could potentially arise (Fig. 3). In practice, of course, this is a multi-dimensional space of which we would only be able to anticipate a few of the principle dimensions. This "possibility space" will be explored by individuals and groups who explore the pay-offs of new behaviour. In biology, genetic mechanism ensures that different possibilities are explored, and off-spring, off-spring of off-spring and so on, spread out over time from any pure condition. In human systems the imperfections and subjectivity of existence mean that techniques and behaviours are never passed on exactly, and therefore that exploration and innovation are always present as a result of the individuality and contextual nature of experience. Physical constraints mean that some behaviours do better than others, and so imitation and growth lead to the increase of some behaviours and the decline of others.
By considering dynamic equations in which their is a "diffusion" outwards in character space from any behaviour that is present, we can see how such a system would evolve. If there are types of behaviour with higher and lower pay-offs, then the diffusion "up-hill" is gradually amplified, that "down-hill" is suppressed, and the "average" for the whole population moves higher up the slope. This is the mechanism by which adaptation takes place. This demonstrates the vital part played by exploratory, non-average behaviour, and showed that, in the long term, evolution selects for populations with the ability to learn, rather than for populations with optimal, but fixed, behaviour.

The self-organizing geographic models developed previously (Allen and Allen \& Sanglier 1977-1990) are a simple particular case of these general ideas. Instead of some "behaviour" space, what we have is real, geographic space. Individuals of any particular type, $\mathrm{X}$, all differ from one another by being located at different points in space. By using distributions of choice and behaviour around an average, the microscopic diversity of individuals is taken into account, and this allows the "exploration" of seemingly unpopular, irrational and non-average decisions. In this way, changes in the "pay-offs" for novel behaviour can be detected

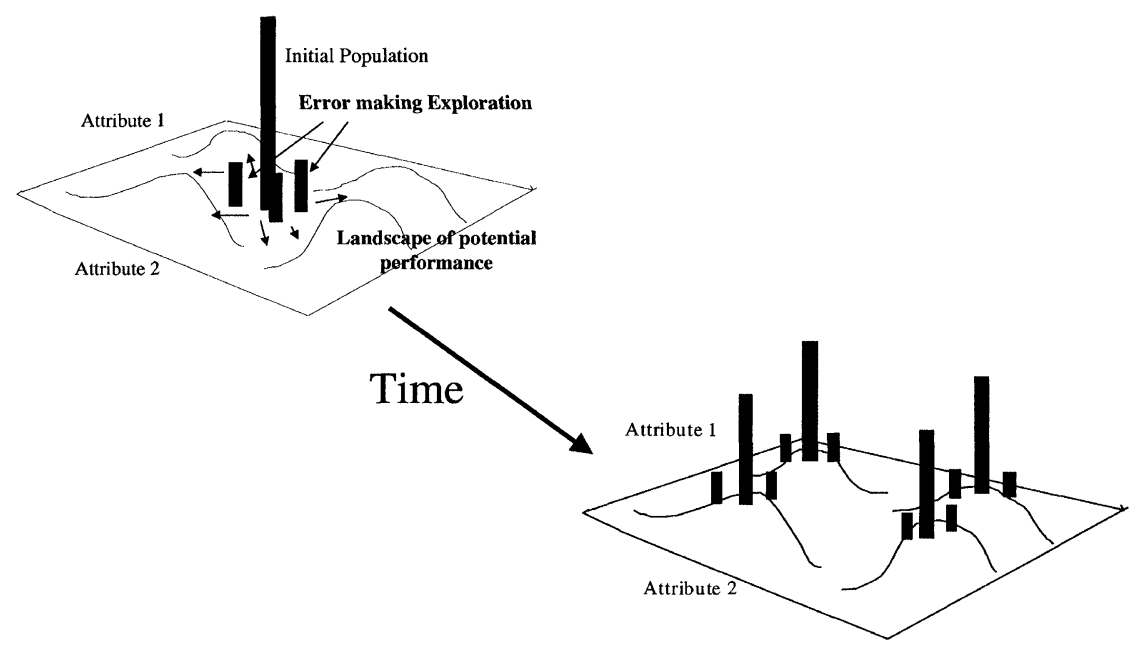

FIGURE 3 The effects of behavioural exploration in possibility space are structural change. 
in the system, and innovations can take off. In this case, it concerns "spatial" innovations, such as the spontaneous emergence of new centres of employment, or of peripheral shopping centres, of industrial satellites and so on. Because of the presence of positive feedback loops, there were many possible final states to which the system can tend, depending on the precise position and timing of non-average events. Information can only come from the paths that were actually taken, not from those that were not and because of this, patterns of change feed upon themselves, and self-reinforcement of growth and decline are the result. Instead of an objective rationality expressing genuine comparative advantages, the beliefs and the structures co-evolve (Allen and Lesser, 1991).

In this section we shall take the evolutionary models a stage further and examine the mutual coevolution of different populations. Instead of considering the evolution of techniques and behaviours in a fixed landscape expressing higher/lower payoffs, we shall allow for the fact that the "pay-offs", the adaptive landscapes, are really generated by the interactions of a population with the other populations in the system. In the space of "possibilities" closely similar behaviours are considered to be most in competition with each other, since they require similar resources, and must find a similar niche in the system. However, we assume that in this particular dimension there is some "distance" in character space, some level of dissimilarity, at which two behaviours do not compete.

During the initial phase of an experiment in which we start off with a single population in an "empty" resource space, resources are plentiful, the centre of the distribution, the average type, grows better than the eccentrics at the edge. The population forms a sharp spike, with the diffusing eccentrics suppressed by their unsuccessful competition with the average type. However, any single behaviour can only grow until it reaches the limits set by its input requirements, or in the case of an economic activity, by the market limit for any particular product. After this, it is the "eccentrics", the "errormakers" that grow more successfully than the "average type", and the population identity becomes unstable. The single sharply spiked distribution spreads, and splits into new populations that climb the evolutionary landscape that has been created, leading away from the ancestral type. The new populations move away from each other, and grow until in their turn they reach the limits of their new normality, whereupon they also split into new behaviours, gradually filling the resource spectrum.

In Fig. 4 we see the changing quatitative structure of the system over time, in some two-dimensional possibility space. In this way, instead of simply evolving towards the peaks of a fixed evolutionary landscape, through their interactions populations really create the landscape upon which they move, and by moving across it change it. So the different behaviours present grow, split off, and gradually fill the possibility space with an "ecology" of activities, each identity and role being formed by the mutual interaction and identities of the others. The limit of such a process would be given by the amount of energy that is available for useful work that can be accessed by the "technological" possibilities potentially open to the system. This means that evolutionary processes would explore and reinforce mutually consistent technologies and strategies that capture parts of the energy flows through the system and use them to build and maintain their necessary internal structure. The limit would be set by the amount of available exergy.

While the "error-making" and inventive capacity of the system in our simulation is a constant fraction of the activity present at any time, the system evolves in discontinuous steps of instability, separated by periods of taxonomic stability. In other words, there are times when the system structure can suppress the incipient instabilities caused by innovative exploration of its inhabitants, and there are other times when it cannot suppress them, and a new population emerges.

Although, competition helps to "drive" the exploration process, what is observed is that a system with "error-making" explorations of behaviour evolves towards structures which express synergetic complementarities. In other words, evolution although 

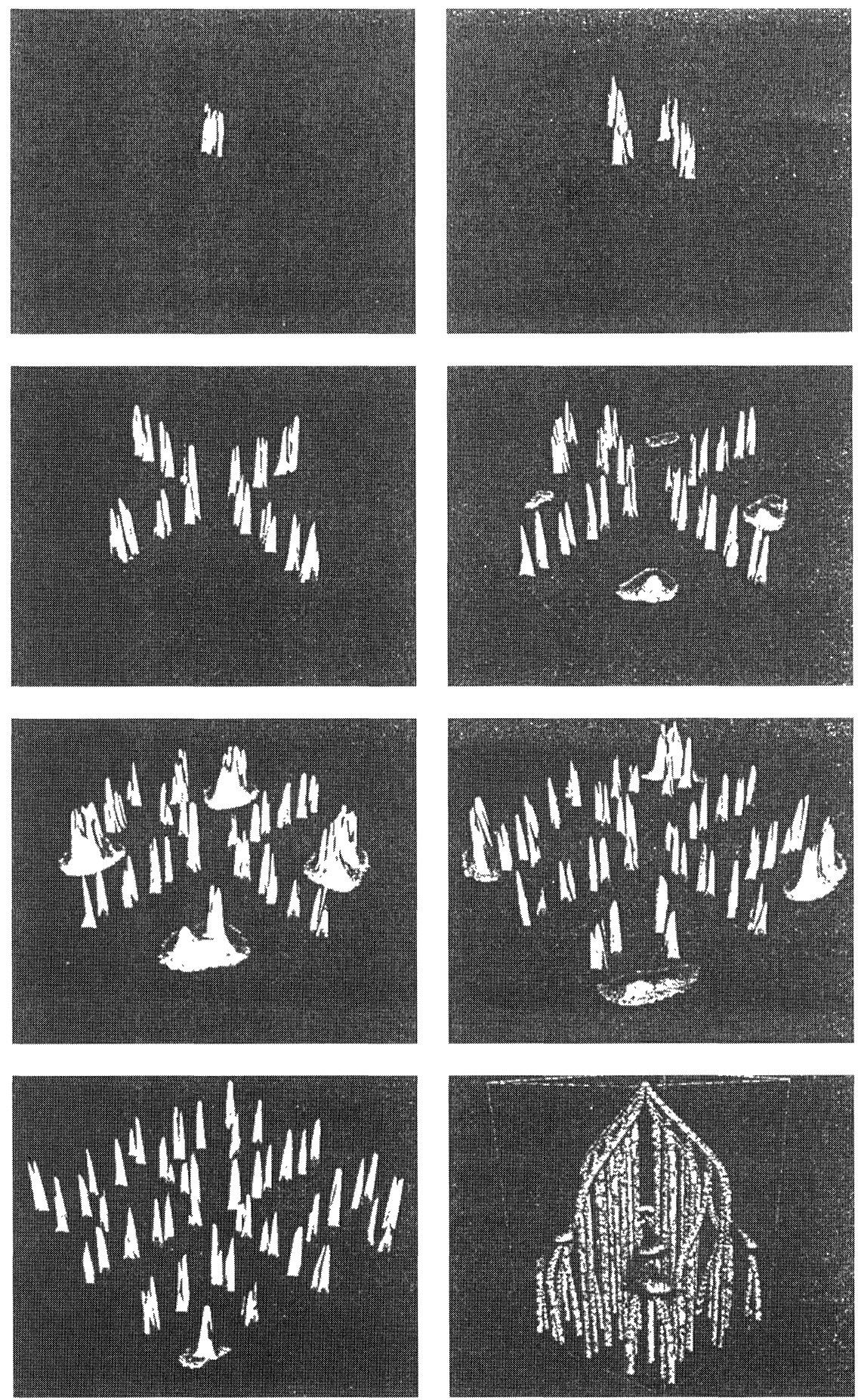

FIGURE 4 In this case the landscape explored by the emergent behaviours is shaped by them. Periods of stuctural stability are separated by periods of change, depending on whether the system can control its own error-making or not. 
driven to explore by error-making and competition, evolves cooperative structures. The synergy can be expressed either through "self-symbiotic" terms, where the consequences of a behaviour in addition to consuming resources is favourable to itself, or through interactions involving pairs, triplets, and so on. This corresponds to the emergence of "hypercycles" (Eigen and Schuster, 1979).

Several important points can now be made. Firstly, a successful and sustainable evolutionary system will clearly be one in which there is freedom for imagination and creativity to explore at the individual level, and to seek out complementarities and loops of positive feedback which will generate a stable community of actors. Secondly, the selforganization of our system leads to a highly cooperative system, where the competition per individual is low, but where loops of positive feedback and synergy are high. In other words, the free evolution of the different populations, each seeking its own growth, leads to a system which is more cooperative than competitive. The vision of a modern, free market economy leading to, and requiring a cut-throat society where selfish competitivity dominates, is shown to be false, at least in this simple case.

From our example, the discovery of cooperativities, and the formation of communities of players with a shared interest in each others success is the outcome of the evolutionary process. The third important point, particularly for scientists, is that it would be impossible to discern the "correct" model equations even for our simple 20 population problem, from observing the population dynamics of the system. Because any single behaviour could be playing a positive, or negative role in a self, or pair or triplet, etc. interaction, it would be impossible to "untangle" its interactions and write down its equations simply by noting the population's growth or decline. The system itself, through the errormaking search process can find stable arrangements of multiple actors, and can self-organize a balance between the actors in play, and the interactions that they bring with them, but this does not mean that we can deduce what the web of interactions really is. This certainly poses problems for the rational analysis of situations, since this must rely on an understanding of the consequences of the different interactions that are believed to be present. It is also true that although we would not be able to "guess" how to arrange the populations to form a stable community, evolution can find how to do this itself. It is the essence of self-organization.

Clearly, if we cannot really know how the circles of influence are formed by looking at the data, the only choice would be to ask the actors involved, in the case of a human system. And this in turn would raise the question of whether people really understand the roots of their own situation, and the influences of the functional, emotional and historical links that build, maintain and cast down organizations and institutions. The loops of positive feedback that build structure introduce a truly collective aspect to any profound understanding of their nature, and this will be beyond any simple rational analysis, used in a goal-seeking local context.

\section{SELF-ORGANIZATION OF CITIES AND REGIONS}

In this section, the ideas of "self-organization" are applied to the development of cities, with a view to establishing the basis for a decision support framework capable of exploring the longer term consequences of decisions, policies and of technology change. We hope from this to be able to build a model which, at least, can predict the sort of structure that may evolve under a certain scenario, with the accent on the qualitative features of that structure, rather than on quantitative accuracy.

The first step in the operation is to choose the significant actors of the system, whose decisions, and the interplay of these, will cause the urban system to evolve. In agreement with much previous work, particularly, for example, the philosophy of a Lowry-type model, we first include the basic sector of employment for the city, and, in particular, two radically different components of this; the industrial base and the business and financial 
employment. Then we consider the demand for goods and services, which will give rise to a local manufacturing and maintenance sector, as well as to tertiary service employment, generated by the population of the city and by the basic sectors. We shall suppose that there are two levels: frequently required, short-range services and more specialized, rarer long-range set. The residents of the city, depending on their type of employment, will exhibit a range of socio-economic behaviour, and for this we have supposed two populations corresponding essentially to "blue" and "white" collar workers.

This is our "taxonomy" of the city. In reality, over long times these variables will change, as a "blue collar" worker ceases to "be" what he was, and "white collar" worker splits into different types and classes, and new industries and activities appear. Nevertheless, for the model we shall develop, these categories will be considered as sufficiently stable in their locational preferences for the time period that we want to consider, that the categories remain coherent and meaningful during the simulation. Having specified the variables, we now need to define the mechanisms that cause the changes in value of these variables in each zone. These mechanisms express the average effects of individual events or decisions which lead to the growth or decline of people or jobs of a given type in a zone, or to their in or out migration. In other words they capture the effects of birth, death, and migration of people and of jobs.

While birth and death rates are cultural and social parameters reflecting the religious, social and economic circumstances of individuals, the creation or reduction of jobs in a particular sector reflects in the longer term the profitability of that sector in that zone. If for example, demand exceeds supply in the retail sector in a given zone, then the excess profits that are possible will lead to investment and job creation. This will increase supply and potentially reduce the excess profits, but in so doing it will have changed the distribution of population as the new jobs created lead to re-locations of the employees, and to the transfer of their demands for goods and services to the neighbourhood. This in turn will change the pattern of profitability in the other sectors, and will lead to the further creation of jobs and of population. So, the linkages between people and jobs, and jobs and people through the spatial expression of intermediate and final demand will lead to a complex cascade of change and readjustment as the city grows.

In order to model the mechanisms governing the location and re-location pattern, the investment pattern, we need to model not just the behaviour that is observed in the data, but the underlying reasons that lie behind it. In other words, we need to represent the locational criteria of the different types of actor, and the changing opportunities that they perceive around them, and from this to generate our "urban dynamic". The model is therefore based on the interaction mechanisms of these variables, which in essence require a knowledge of the values and preferences of the different types of actors represented by the variables, and, of course, how these values conflict and reinforce each other as the system evolves. In other words, the model is driven by the actions and behaviours that characterize actors who are fulfilling certain roles or tasks corresponding to their job requirements, and also to their cultural "identity" which dictates how they may wish to be viewed, and also their pattern of final consumption.

The professional roles that actors adopt concern the successful functioning of their activities, and these therefore reflect their beliefs concerning the "functional requirements" of jobs in the different sectors. So, heavy industry must ship in large quantities of raw materials, engage in energy and material intensive transformation processes, get rid of wastes, and then ship out the finished products. Its activities lead to a characteristic "value-added per square metre", which sets limits on the rents which still allow profits, and add to the locational criteria which apply. Similarly, office headquarters for financial institutions for example, need to be at centres of communication, in prestigious surroundings, preferably where they can meet with other similar professionals over lunches, so as to keep up with the news and with the latest trends. Obviously, 
logistic considerations play a vital role in the commercial and retailing sectors, and the spatial organization, or rather self-organization of supply chains can be seen as the underlying dynamic of urban and regional development. From the interdependent locational criteria that characterize the different urban actors, needing to be near their customers, or to cheap accessible land, etc. our model consists of equations which express these as a set of interacting mechanisms.

The model is inspired by data coming from Brussels, and so comes much closer to really describing reality. The interaction scheme is shown in Fig. 5.

There are five types of employers: industrial, financial, two levels of tertiary activity, and local industry. Each of these has its own locational criteria involving land and their infrastructural requirements, as well as differing types of access to road, rail, canal or to air communication. They also have differing labour requirements both in terms of the numher of jobs created per square metre and in the socio-economic group of employees.
Thus, heavy industry requires overwhelmingly blue collar labour, whereas the financial and business firms of the central business district employ almost entirely white collar citizens. We have therefore chosen to distinguish between these two types of residents, and these together with the five types of employers from our 'mechanics' of seven mutually interacting variables.

This model has been reported elsewhere (Allen et al., 1983) some years ago, but recently, the whole system has been redeveloped for the PC environment and the models are again a focus of interest (Fig. 6). We can include the various different transporation networks that traverse and link the different parts of urban space. All the perceived "distances" and decisions concerning residential location, shopping destinations, etc. can be made with respect to the perceived attractiveness of the different possible transport modes and routes available. Can the qualitative evolution of Brussels be "generated" spontaneously by our model? If this is possible, then it implies that the model contains the "reasons" why the structure of Brussels has

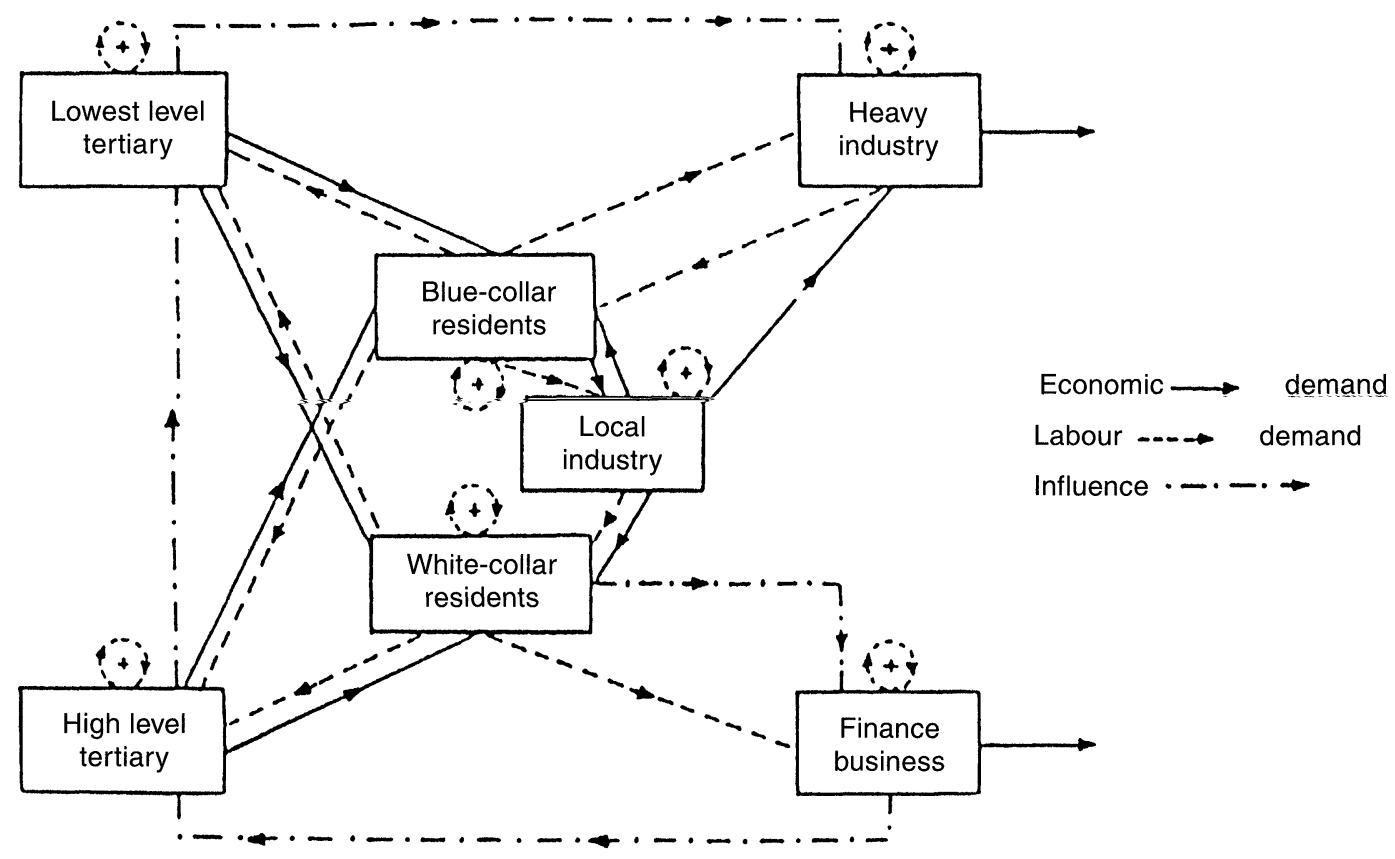

FIGURE 5 The interaction scheme for a dynamic, spatially self-organizing urban model. 


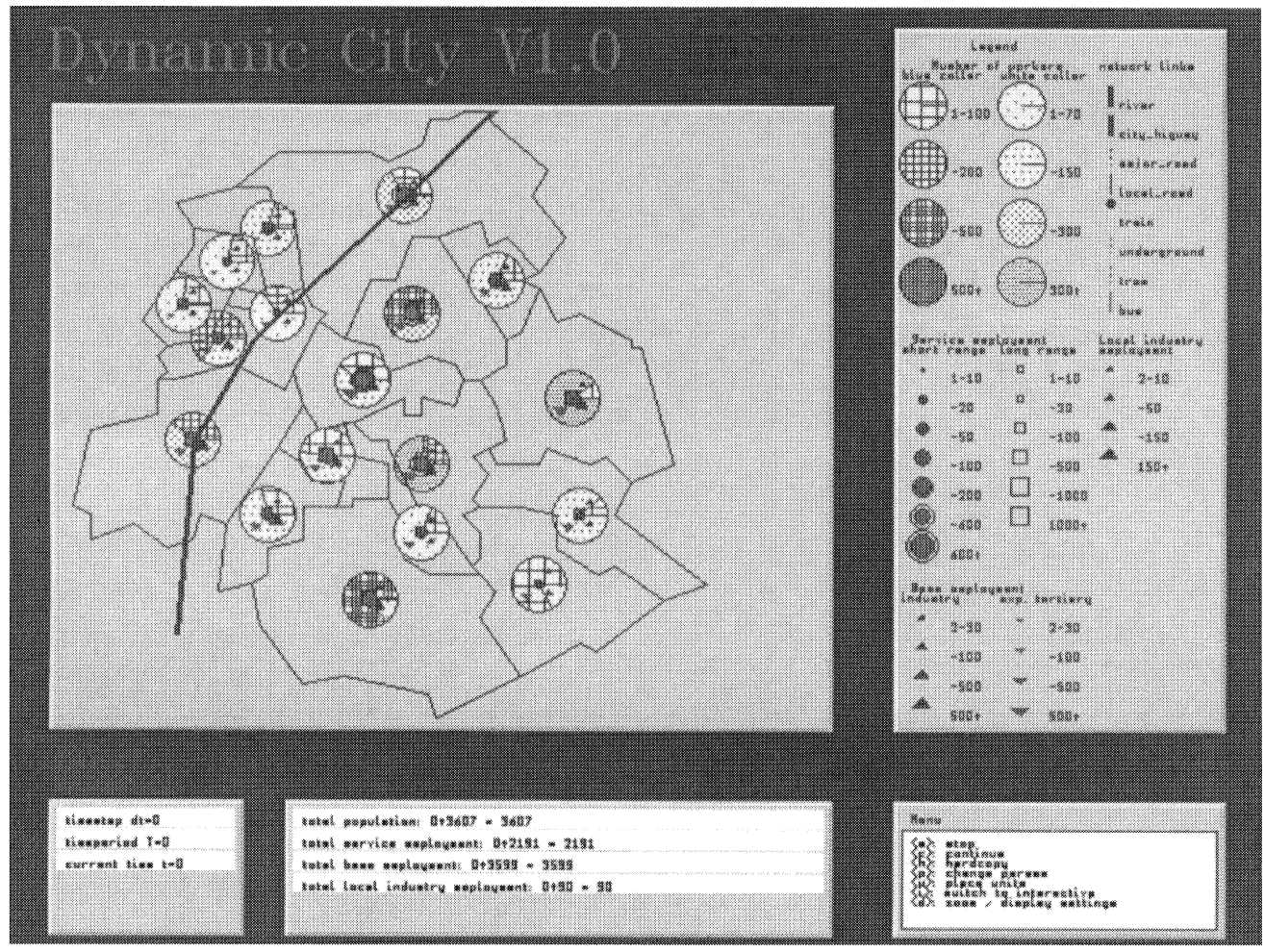

FIGURE 6 The screen of our PC based "Brussaville" model developed by T. Buchendorfer.

become what it has, and more importantly therefore, why this might change in the future. It allows an exploration of the possible limits to the stability of this structure, indicating alternative future structures that might evolve under different possible policies, investment decisions and changing scenarios of in and out migration.

Our basic set of urban mechanisms is represented by a set of non-linear differential equations each of which describes the time evolution of the number of jobs or residents of a particular type at a given point. In a homogeneous space one possible solution of these equations would be to have an equal distribution of all variables on all points. Such a non-city, although theoretically possible, corresponds to an unstable solution, and any fluctuations by actors around this solution will result in a higher pay-off, and this will drive the system to some structural distribution of actors, with varying amounts of concentration and decentralization.
There are two reasons behind the structure of the system: the first is due to the non-linear interaction mechanisms which give rise to instabilities as mentioned above. The second is due to the spatial heterogeneity of the terrain and of the transportation networks.

The road network takes into account three different qualities of road and the public transport networks considered are those of the train, bus, metro and tram. Each link of each network depends on the relative sensitivity of an actor to these. We have therefore a dynamic land-use-transportation model which permits the multiple repercussions involved in the various decisions concerning land use or transportation to be explored as the effects are propagated, damped or amplified around our interactive scheme.

We see that our urban system evolves to a complex interlocked structure of mutually dependent concentrations. We have two poles of heavy 
industry, and a distribution of blue collar residents reflecting this.

Financial and business employment in the city centre begins to spread through the urban space. Then, it exceeds a threshold at a point adjacent to the centre and grows dramatically there, causing the decentralized locations throughout the city to decrease. The white collar and blue collar residents spread out, many live outside the system, according to the accessibilities of the networks, and a spatial hierarchy of shopping centres appears, serving the suburban population and encouraging further urban sprawl. The model generates not only the locations of employment and residents, but also the daily traffic flows along the different branches of the transport network, and the feedback effects on location patterns that are caused by the changed accessibilities due to congestion. This describes the evolution of our system according to the deterministic equations of our model, and starting from the particular initial conditions that we have used. The model can now be used to explore some simple policy options or change in circumstances.

The ideas sketched out in our first section tell us that the deterministic equations governing the average behaviour of the elements of a complex system are in fact insufficient to determine precisely the state of the system and even its qualitative character. This is because there could be many different spatial instabilities, leading along different trajectories. Only the effects of factors and events not included in the differential equations break this ambiguity and decide which branch precisely the system will really be on! In this way an event of historical significance is one which is not contained in the average behaviour of the elements.

This tells us that choice really exists and that planning, policy and intervention need not be based only on self-interest or pious hope. It is necessary to know something of the consequences of the different options available, in order to compare and evaluate the choices. And these evaluations should be made in a broad set of dimensions, corresponding to the different aspects of "quality of life" that the various inhabitants of the system may consider important. Clearly, our self-organizing models are rather well suited to exploring the question of "sustainability", since they examine the longer term implications of decisions and policies, including potential radical re-structuring of urban space. They generate the urban macrostructure, the patterns of flows and of activities, from the microstructure within zones, in turn changing the occupation, the pressures and the constraints experienced within them, which feeds on to the macrostructure. Sustainability must be about the possibility of finding micro- and macrostructures which are mutually compatible, and that can coexist.

While the model can be used for evaluation, of course the actual decision concerning which action or policy should be pursued is a value judgment which must be made by political decision makers on behalf of the community. The weighting accorded to different social groups, to the long or the short term, and to the degree of disparity between groups that is reasonable, are matters of social and political judgment. However, in the absence of a successful model, this judgement can be exercised on entirely fictitious future perspectives. Developers may depict the desperate need for some installation, with future demand soaring, job creation, local economic revival and increasing local property values, and all these with apparently no harm, indeed positively good, for the environment. Objectors, however, will paint an image of the same installation in terms of the destruction of natural beauty or of an area of historical and architectural interest, or threatened ecological collapse, of future overcapacity in the area offering, therefore, only slight short term economic benefits which certainly would not offset the serious reduction in property values that must be expected.

The self-organizing models proposed here may provide a step towards an improved situation in which the significant consequences of policy can be explored, not just in their narrow context, but also in the wider, systemic one, since the action may set off a chain of events and repercussions throughout the system. Most disagreements concerning decisions are not about the immediate short term effects 
and the narrow context of construction costs, floor area, kilowatts required, immediate traffic changes, etc., but instead concern the long term and wider implications of the decision, which is what our models may be suitable for exploring.

In the different possible outcomes resulting from different actions or policies, the distances travelled to work may well be very different, as are the costs of shopping trips or the distribution of retail centres. Furthermore, not only are the spatial distributions of the variables different, but also the global quantities of industrial and tertiary activity, and of white and blue collar residents are modified. This underlines the fact that global quantities are not constraints on an evolution, but on the contrary are observables which are generated by the local events in the system. Our approach is generic, being based on simple assumptions about individual preferences in the sense that it should be contrasted with one based on observed behaviour of a particular system. Our simple interacting locational criteria can generate many different cities, and in this way offer us the mechanics of our system on which the circumstances and history of each city will act, generating as evolutionary tree of possibilities of qualitatively different urban structures.

However, in order for a model such as this to be useful in the context of planning and as a Decision Support Tool for policies of various kinds, we need to see how it links to the microscopic reality within each spatial zone, and also to the larger system of cities within which it sits.

\section{NESTED COMPLEXITY}

The models above allow us to explore how two particular levels of description are linked by the interactive mechanisms resulting from the decisions and behaviours of their inhabitants. The levels are those the system as a whole (Brussels for example), and that of the 40 zones chosen to describe its spatial structure. Each zone is characterized by rather aggregate measures of accessibility and housing and land availability, and is populated by inhabitants with behaviour that is distributed around an average. The "attractivity" of a zone is given on average, and therefore fails to represent explicitly the possible existence of different sublocalities with perhaps very different characteristics. The model as it stands would therefore fail to entirely capture the real behaviour of firms and residents locating there, who may well find localities within it which are highly attractive and others which are quite unsuitable. In order to improve our representation therefore, we need to examine the lower level of description, and to build up the parameters which characterize a zone as the result of a more detailed calculation carried out at the microscopic level.

This could be done in a variety of possible ways, and one simple way would be to examine the sublocations in terms of their attractivity, using the criteria developed in the urban model above. Inside each zone therefore, we may trace the patterns of accessibility to the external zones, as well as of the suitability of land, the type of housing and the qualities of the different neighbourhoods. From this, at any given time the different types of firms, and inhabitants could be distributed through the zone according to the suitability of each parcel within the zone. This is illustrated in Fig. 7.

It is also at this point that these models link up to several other pieces of research that are on-going. Firstly, this urban model can be seen as sitting within an evolving urban hierarchy, and at present a generic simulation framework is being developed to look at this (Buza et al., 1995). It also links to the work of White and Engelen (1993a,b), who have developed cellular automota rules which generate the locational and co-locational features that characterize a particular city locally. It links also to spatial syntax of Hillier and Hanson (1984), Hillier and coworkers $(1992,1993)$ which looks at the actual perceptions that people have of the spatial system, and how the pattern of movement and location reflects this, and in turn structure space. However, according to the "self-organizing" approach presented in this paper, we would attempt 


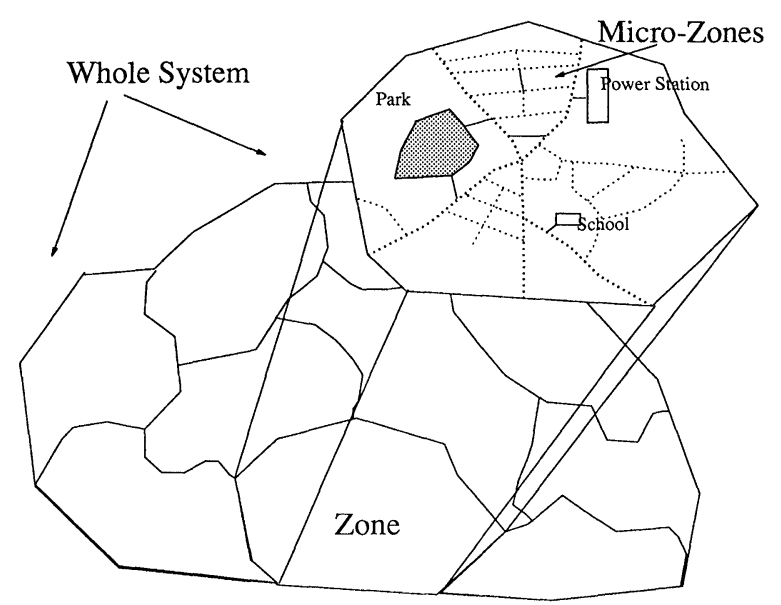

FIGURE 7 The microdistibution of employment and of residencies can be modelled using the attractivities expressing actors preferences, and the very local circumstances.

to identify the factors that influence microlocation, and in particular the non-linearities that lead to clustering at that scale.

Another interesting link is to the work of Batty and Longley (1994), which looks at the fractal nature of the spatial patterns both of the boundaries of cities and also of manner in which jobs and residences fill the space. Inside our self-organizing macromodel of large zones, the constraints and pressures for the growth or decline of different types of inhabitant or employment can be enacted in detail using the micromodel, and from this a more precise and sensitive response will be generated within the localities, giving rise to more accurate representation of the "average" parameters characterizing the zone. This in turn will affect the macrodynamics, and through this the microrepercussions in the other zones.

We can represent the attractivity of a zone as resulting from that of its constituent microzones, which may reflect the existence of "functionally efficient" clusterings. Clearly, however, a microzone can only contribute to the "attractivity" of the zone of which it is part, if it is connected through the different transport and communication networks to the outside of the zone. So, if there were only a single road, for example, traversing a zone, then only those microzones lying along the road could contribute to the attractivity of the zone. The "fractal filling" factor observed by Batty and Longley would be 1 . Conversly, if such a dense network existed that every microzone of the zone was connected to the outside world, then the fractal filling factor would be 2, total two-dimensional filling is possible. However, depending on the scale, the figure would normally be somewhere between these two limits.

Regional and national models were developed which showed how the mutual interaction of urban centres was both influenced by, and in its turn influenced, the flows of investment and of migrants. From this an evolutionary model of Belgium, for example, was developed and has been described in detail elsewhere (Sanglier and Allen, 1989). Clearly, the model which operated in terms of the spatial pattern of employment and of population in the Provinces of Belgium, provides the context within which the model of Brussels has to be placed. The changing investment pattern that affected Brussels was in part understandable in terms of the pattern accross the Belgian Provinces. It also reflected, of course, the place of Belgium within the European Union, and the very large proportion of trade crossing its frontiers, and the growth of employment related to the location of European institutions in Brussels, and the accompanying multipliers of 
financial and business organizations locating to their proximity.

However, in general, the overall "success" of a city is conditioned by two main factors: the costs and benefits that result from its location within the national/international framework, and seconds those arising from its internal structure. So, cities that suffer high levels of congestion, have poor infrastructure, dissatisfied residents with poor educational and training levels, environmental problems and high taxes, for example, will not be characterized by the same parameters of "functioning" as they would be if they had better internal structures and facilities. Because of this, the particularities of the internal structure, and the success or failure of urban centres with respect to their inhabitants penetrate upwards to affect their capacity to attract investment and migrants, and hence their long term growth. These models provide a basis for considering economic development, settlement pattern, urban structure and transport and energy quite successfully. Future research work, however, will be directed at developing a truly hierarchical framework, which will automatically allow at least two levels of description to be modelled simultaneously, and simulate the dynamic dialogue between the two levels, as micro- and macrostructure emerge, and mutually interact. Ultimately, local behaviours are influenced by, and influence really macrostructures such as for example, the climate.

\section{AN INTEGRATED FRAMEWORK FOR SOCIO-ECONOMIC, TECHNOLOGICAL AND ENVIRONMENTAL EVOLUTION}

With "sustainability" a fashionable word, there is a general understanding of the need to consider the long term consequences of our present urban "lifestyle". This is a good thing, although it comes somewhat late in the day. The problem is though, that there is no clear view as to the meaning of "sustainability", nor the manner in which it can be attained. In the UK, government interest has focused on "economic" sustainability, which is translated into attempts to encourage commercial ventures with new, cleaner technology products, and to promote energy savings, waste recycling and charging full economic costs for things. This of course misses the point that, perhaps it could be the market system itself that threatens sustainablity, by forcing short term high economic returns on businesses.

If we think seriously about "sustainability", then it should concern the preservation of the options for future productive activities, and should involve a whole range of measures reflecting our "quality of life". In other words, in order to evaluate the contribution a policy, technology or action might make to "sustainability", we would require an integrated framework that could explore its overall, long term effects. For technologies, for example, it would include the implications of the production, use and disposal phases of the products, and also the overall effects of the chain of effects such as spatial re-organization, which would be involved.

The kinds of model described above clearly offer a possible basis for such an integrated framework, but in the examples described, environmental variables are only taken into account in a very simple manner, and the "sustainability" in environmental terms is not addressed very clearly. An early attempt to build an integrated decision support system was that of the Senegal Model, which combined a self-organizing model of demography and economic activities in the different regions of Senegal, but also linked this to water demands, soil conditions, and climatic changes (Fig. 8).

The model allows possible development strategies to be explored as the changes affect the decision making of potential migrants, and of economic activities. In particular, the probable effects of costly infrastructural investments such as roads, or the very large Senegal River development activities can be assessed, and the effects of different choices examined. Unfortunately, this potentially invaluable tool, developed with EU funding, although strongly requested by Senegalese Government Ministers, has not received the necessary EU 


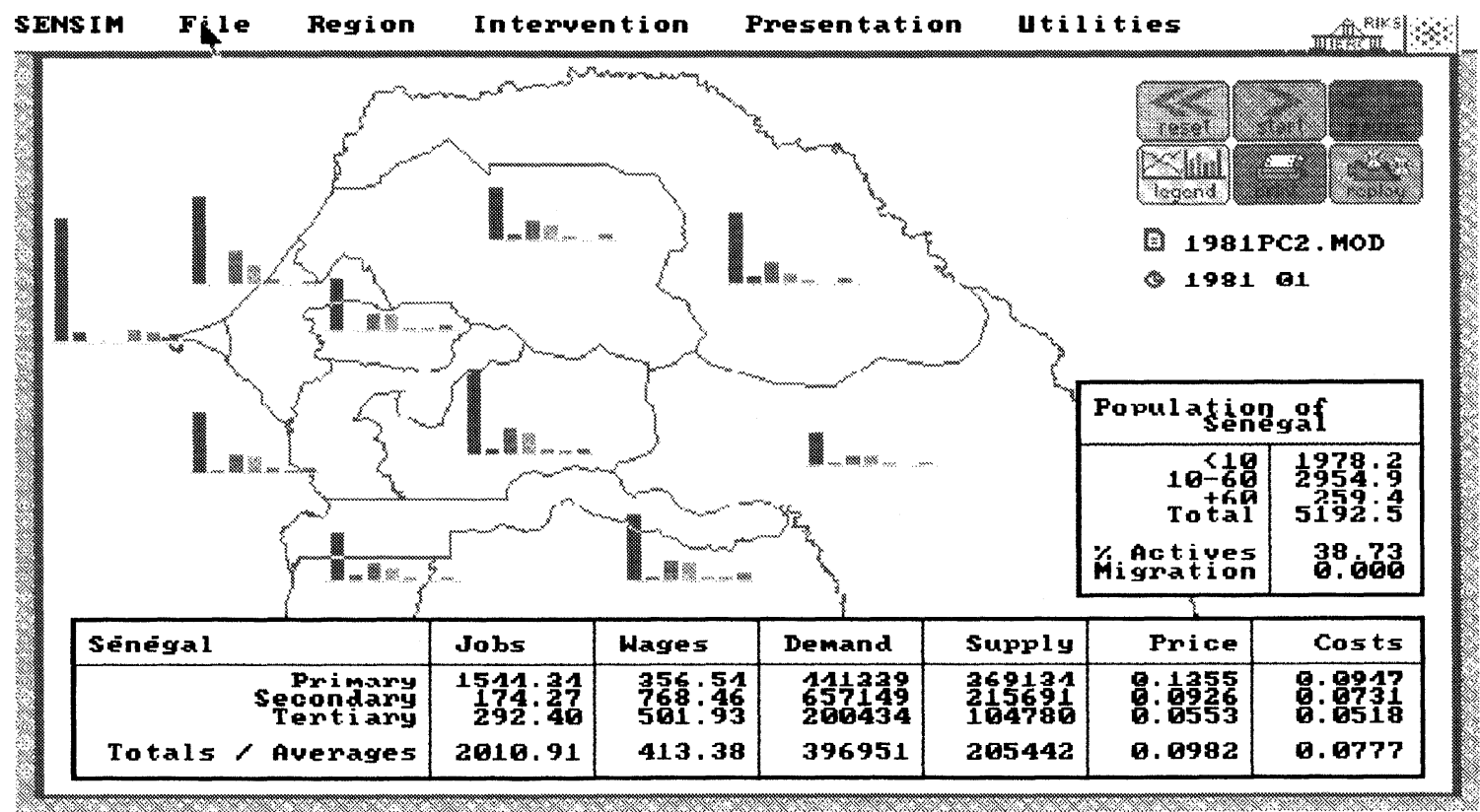

FIGURE 8 The opening screen of the Senegal Model. It provides dynamics equations linking regional demography, economic activities and soil, water and climate conditions.

funding to introduce it into the Planning Departments of Senegal, and so has never been implemented.

Another example of an integrated self-organizing model linking socio-economic variables to environmental ones for the whole Escaut/Scheldt river basin (Fig. 9). The changing pattern of inputs to the river system and the groundwater was generated from the changing pattern of population, employment and land-use of an extended Belgian model which included the relevant part of Northern France. These inputs are obviously subject to policy and regulatory decisions, whose effects therefore can be explored using the model. These human activities and impacts were then connected to an ecological, biochemical and physical model of the river basin, which allowed the calculation of such variables as the concentrations of oxygen, phosphates, nitrates, phyto and zooplankton, bacterial and organic wastes in each branch of the river as the water descended to the estuary. So, the water quality in the different branches, the eutrophication of the lower reaches, the output of phosphates and nitrates to the North Sea, and much else, could be simulated by the integrated model. In this way, possible environmental policies and regulations could be tested on the system as a whole, showing their complex consequences.

For example, improved water treatment of urban outflows to the river, led to greater discharges of nitrate and phosphate to the sea, and to eutrophication, because the lower bacteria concentrations in the river were not able to de-nitrify as much of the nitrates as before. The model also allows an evaluation of the most effective actions/locations for a given investment, and explores the chain of effects that really accompany any particular environmental measure.

Another example of an integrated model that allows an examination of sustainable land-uses, and links environmental and socic-economic variables is that of a model of agriculture in the Argolid plain of Greece (Archaeomedes Report, 1994) (Fig. 10). The on-going process of urbanization is running fast in the Mediterranean, and the coastal areas are all the scene of increasing urban populations, and of 


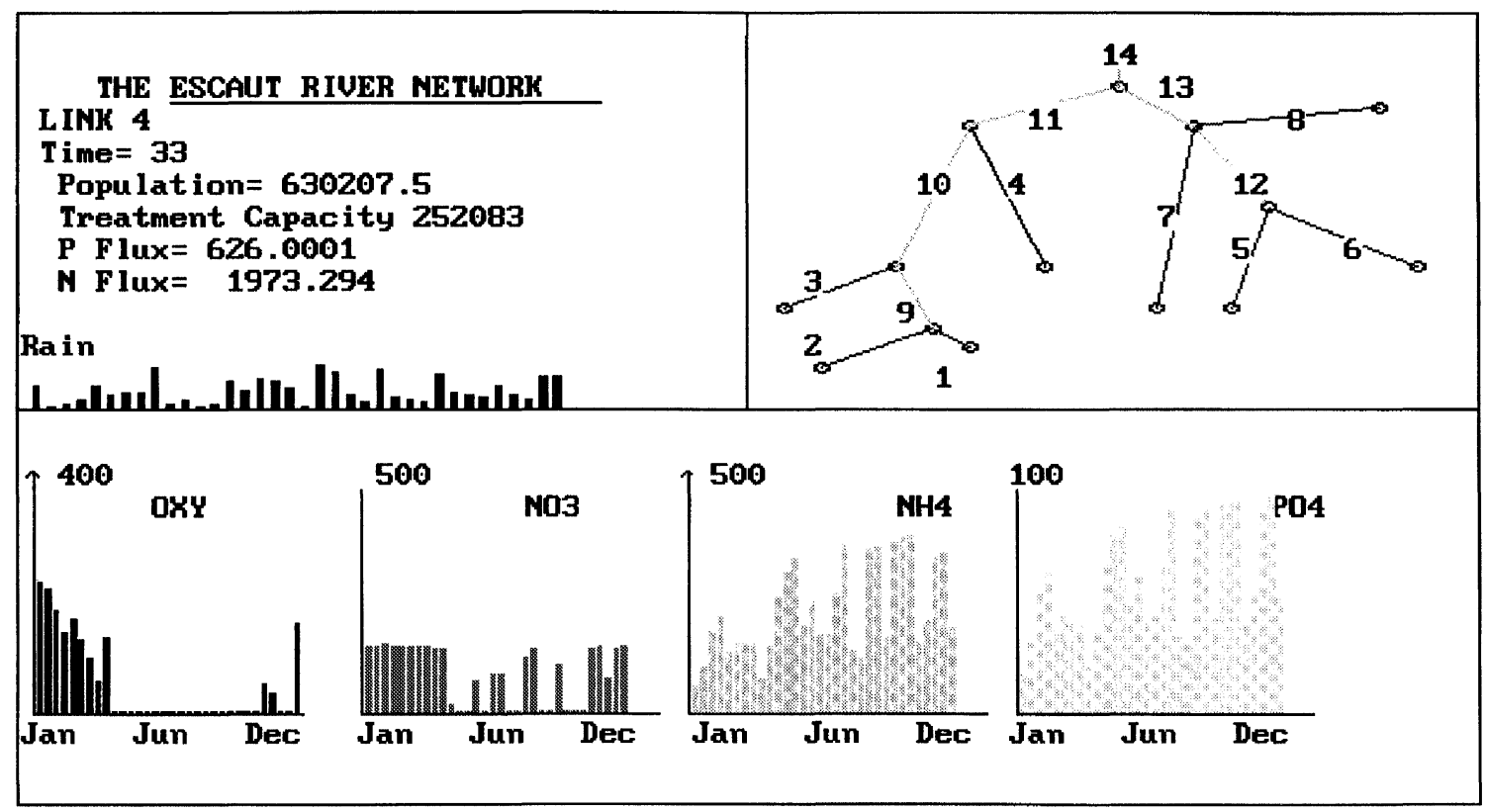

FIGURE 9 The Escaut/Scheldt river basin, integrating a self-organizing socio-economic spatial model with an ecological, biochemical and hydrological river model for environmental policy exploration.

the intensification of agriculture. In an attempt to obtain rates of return on capital that are comparable with those of "urban" activities, traditional farming practices are being replaced by more "modern" ones, with more lucrative crops, requiring increased use of water resources through irrigation. In the case of the Argolid, the increased exploitation of the coastal aquifers has led to the salinization of the aquifers and of the land, and in recent research a dynamic model has been built which successfully generates this self-destructive process which farmers have engaged upon. It is of interest because it shows how well intentioned policies at one level of the system can have a quite negative effect at another level.

In the case of the Argolid, farming has gradually switched from the production of olives and cereals to the irrigated production of citrus fruits. The efforts of the European Commission's policy to avoid the decline of rural areas were crystalized into price support policies, and it is the action of these for citrus fruits that have led the farmers to increase production.
The model considers 7 spatial zones and 3 layers: the surface, the sub-surface layer that may be permeable or not, and the aquifer. The flows of water through the area of study was then modelled by considering the three-dimensional movements of water onto and off the surface, through the subsurface layer if it is permeable, and in and out of the aquifer.

The main human impact has been the decision to grow irrigated crops, and the resulting need to pump water up from wells, boreholes and from canals to maintain growth during the hot, dry summer. Otherwise, for geological times, the winter rainfall has fed the aquifers and springs, and given rise to a net positive hydrostatic pressure throughout the zone. Our model considers the chain of effects of the pumping of underground water as the area of irrigated crops has increased.

The dynamic model that has been developed considers that crop choice decisions are made annually, and that this sets out the agricultural requirements for water for the next 12 months. The amount of irrigation that will be required then depends on the 


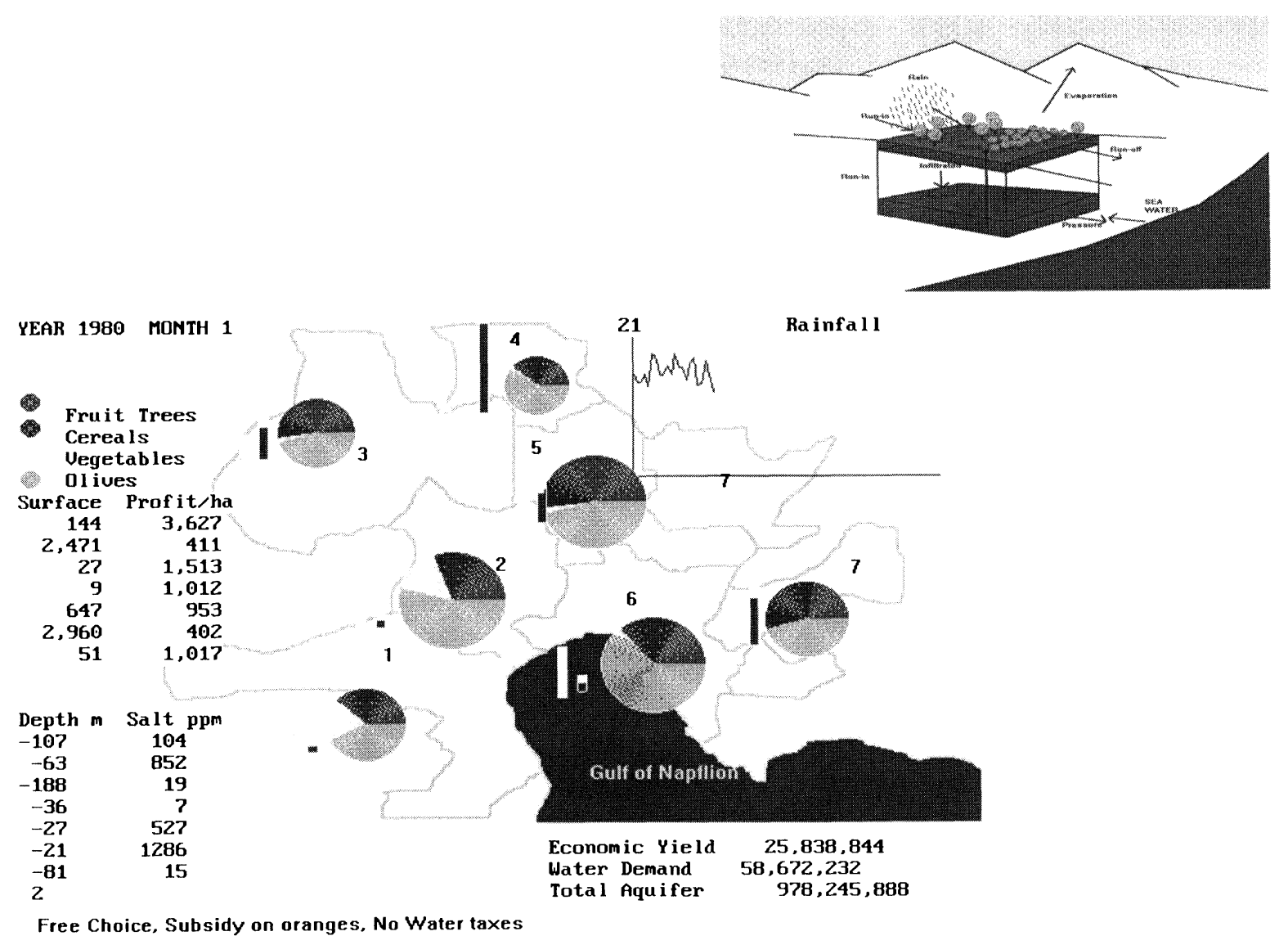

FIGURE 10 The Argolid plain. Modern agriculture based on irrigation.

profile of crop needs throughout the succeeding weeks of the year, and the rainfall and the evapotranspiration that actually occurs. The model therefore uses a short time step of 3 days (one tenth of a month) to describe the movement of water and salt over and through the different zones and sections of the model. It simply uses balance equations based on water and salt accounts of each sections.

Without discussing the detail of these calculations, we can simply summarize the model by saying that it allows us to model the farmer's response to his circumstances: market prices and uncertainties, crop choice, and water requirements. This then allows us to model the change in surface and aquifer water, and the salt concentrations in both as sea water is drawn into the aquifers. This in turn pro- duces a pattern of salinization, the demand from farmers for fresh water to be supplied to them by canal, from somewhere else, and finally the need to increase production and water consumption to make up for falling yields.

The medium which transports the salt around the system is water. Initially, before large scale irrigation occurred, there was a gentle, positive hydraulic head throughout the system, which meant that the aquifers were pure, and that there were some marshy areas of land. There was a steady transfer of the catchment water to the sea. However, as the hectares of irrigated land were increased, the overall water balance of the groundwater changed, and at around 1960, it became negative. The coastal zone irrigation rapidly led to the incursion of seawater 
into the groundwater, with a consequent transfer of salt. The continued irrigation pumping transferred the salty water from the aquifer onto the surface, where, gradually the productivity of the soil was eroded.

In response to this, a first, small canal was built which brought spring water from the western corner of the Argolid, and this water was used for irrigation along the coastal strip. While this allowed intensive fruit tree growing to continue, the farmers further back from the coast continued to expand the area of irrigated crops and hence the amount of water pumped from the aquifer.

The lowered hydraulic pressures led water to feed back from the coastal aquifers, thus transporting sea salt underground some $20 \mathrm{~km}$ inland. Gradually then, the salt problem has increased as a result, so that a large canal project was put in place to deliver spring water over a wide area of the plain. In addition, the lowered water level of the aquifer has meant that farmers in the periphery have found it increasingly difficult to get water at all, and so there is a demand for water to be delivered from the large canal both because of salinization, and because of water demand. The problem is that fresh water is something with a limited supply, and the sources used have also been growing more salty, and so ever greater technological interventions may be called upon to maintain the production of citrus fruits, in an increasingly artificial landscape, totally reliant on costly infrastructure. When we realize that many of the oranges produced are in fact not consumed but buried, to maintain market prices, it seems clear that there is some need to review policy in an integrated fashion.

What is also important is that this situation in the Argolid is being repeated in many other locations, and is in reality, part of the unsustainable hidden reality of urbanization. As populations have shifted to the cities, so the decision makers are increasingly divorced from the reality of the natural system that really supports the cities. Cities not only "selforganize" themselves, but also their own and distant landscapes. The dubious power of economic exchange ensures that cities continue to maintain their supplies, if necessary with more intensive exploitation at greater distances, essentially "stripmining" the world's agricultural land.

There is clearly a need for an integrated framework which will allow an appreciation of the net change in real "wealth", meaning not just the temporary flows of money captured in GNP, but the value of biological potential, the stocks of fertile soil, fresh water and other natural resources, which support the urban as well as the rural population.

Having discussed local issues of environment and human activities, let us turn to the hierarchical level above human activities: that of the planet. In some recent work on climate change and the human response to it, Cousins et al. (1995) have been able to make a first estimate of the impact of human activities, particularly agriculture on the Earth's climate. This resulted from the TIGER project funded by NERC in the UK. The work of Woodward et al. on natural biomes led to the possibility of showing what natural vegetation would be over the planet. This could then be used to establish the geographical parameters of albedo, roughness, etc. relevant to a global climate model of the UK Meteorology Centre. By then comparing this with the vegetation cover that actually exists as a result of human agriculture and animal grazing, a modified picture could be obtained of the world climate pattern that exists today. The differences show us the impact of man's activities thus far on the climate. They are not at all negligible. For example, Europe is some $2^{\circ} \mathrm{C}$ cooler than it would have been if it had not replaced its natural Forests by agriculture. Of course, some other regions are warmer than they would have been, but the important point is that we have already changed the Earth's climate. Indeed, it looks as if the effects of agriculture may already be as great as those feared for $\mathrm{CO}_{2}$ over the next century.

\section{DISCUSSION}

The fundamental basis for these models are the decisions of the different types of individual actors, 
which reflect their values and functional requirements. Although these are represented by very simple rules for each type of actor, when distributed among average and non-average individuals, they give rise to very complex patterns of structure and flow, and to a structural emergence and evolution at the collective level. In turn, the macrostructures that emerge constrain the choices of individuals, and fashion their experience, so that without the knowledge afforded by such models, there may not be any simple relation between the goals of actors, and what really happens to them. Each actor is co-evolving with the structures resulting from the behaviour of all the others, and surprise and uncertainty are part of the result. The "selection" process results from the success or failure of different behaviours and strategies in the competitive and cooperative dynamical game that is running.

The spatial models of urban and regional evolution are examples of this kind of evolution. What emerges are ecologies of populations, clustered into mutually consistent locations and activities, expressing a mixture of competition and symbiosis. This nested hierarchy of structure is the result of evolution, and is not necessarily "optimal" in any simple way, because there are a multiplicity of subjectivities and intentions, fed by a web of imperfect information. The total pattern emerges as a result of the interaction of imperfect patterns of behaviour for each type actor, and what this really means is that there is an intrinsic element of unpredictability in the system. Creativity, and adaptive response are therefore powered by the degree of heterogeneity of the population, and their microscopic diversity.

The idea that evolution leads to a community of interlocking behaviours is an important result. The history of a successful society within a region, is largely a tale of increasing cooperation and complementarity, not competition. An economy is a "complex" of different activities that to some extent "fit together" and need each other. Competition for customers, space, or for natural resources is only one aspect of reality. Others are of familiar suppliers and markets, local skill development and specializa- tion, co-evolution of activities to each other, networks of information flows and solidarities, that lead to a collective generation and shaping of exchanges and discourse within the system.

These ideas help us to understand the origins of coherence in human systems. In classical physics, the smooth behaviour of macrovariables such as temperature and pressure arises from the incoherent, random behaviour of the molecules. It is statistical averaging that leads to smooth behaviour. But, in self-organizing systems, the individual elements really are behaving coherently, either as the result of an external parameter that affects each individual separately, or as the result of co-evolution. For example, the day/night cycle affects everyone separately, and leads to the coherent behaviour of people going to work and coming home. However, the interlocking of activities in such a way that food flows from the fields, through various processing and wrapping stages, and arrives on the supermarket shelves in time for the saturday shopping rush, has demanded an enormous amount of skill and organization, resulting from a long learning process. The working of a modern economy certainly displays great coherence, and the ideas discussed here attempt to show how coherence, and spatial and hierarchical structures emerge through processes of self-organization and that these models can help us anticipate future changes and different possible types of coherent structure that might emerge. This is really what policy exploration should be about.

The evolution of a society is not about a single type of behaviour "winning", through its superior performance, since as we see evolution is characterized more by increasing variety and complexity than the opposite. Instead, it is about the emergence of self-consistent "sets" of activities, with mutually helpful effects on each other. Potential "supply" and "demand" are not given independently of one another. People cannot experience what is not made available, but can only be affected by what is produced. Their lifestyle, demands and preferences are shaped by the supply that really occurs, and so a "learning" dialogue shapes the patterns of 
consumption that develop in the system. Supply affects demand, and vice versa, and cultural structures are formed by the effects of positive and negative feedbacks - imitation, economies of scale, learning by doing, etc. are positive, and competition for attention, market and for resources are negative.

In attempting to model the self-organization of spatial markets, we must consider the possible effects of speculation in human systems. The important point is that the expected return on an investment is what drives investment, but this must depend on what people believe about the system. What people believe affects what happens, and what happens affects what people believe! This is a positive feedback loop which can be understood on the basis of the kind of models which we are developing. It severely affects the outcome of "free markets", as we have seen repeatedly in commodity cycles, land speculation, the prices of almost anything of which there is a limited supply. Instead of free markets necessarily leading to a sensible and effective allocation of investment and resources, we find that prices can be driven by peoples' beliefs, and these can feed on each other resulting in peaks and troughs, and often in massive misallocations of resources and waste. Clearly, the fact that "trend creates trend" offers a considerable opportunity for instability and chaos, and this is only rendered manageable by the diversity of perceptions and motivations of human actors. Models can and are being developed to "learn" robust mutually consistent strategies, and also how to encourage diversity in the face of the mass media, and instantaneous shared information.

Diversity is absolutely vital to the functioning of the system. Social interaction and mutually advantageous exchange can only occur if two actors are different. If they are both identical and "average", then there can be no useful interchange. The evolution of a society and of the urban or regional landscape therefore reflects the specificities of individuals who have different aims, different information and different resources. Imperfect knowledge, and plain ignorance all play a role in smoothing the responses of a population to a given situation and as decisions are made by some individuals, so they change the conditions and constraints on others provoking successive responses and adjustments to the evolving circumstances.

The idea that we can solve our problems by simply releasing the forces of the "free market" is an illusion. The real complexity of the world involves the fact of collective structure, which is not amenable to any simplistic solution, be it central planning, or free markets. The goals and strategies, the ethics and the understanding of individuals, fashion the collective structure that emerges, and give it complex properties, which act on each individual uniquely, and which cannot easily be resumed in a few criteria. Similarly, the collective structure that emerges, enriches and constrains the experiences and choices that are open to individuals, and so one is dealing with the dialogue between individual freedom and beliefs, and the social, cultural, technological and physical realities in which they are embedded, and which they shape.

The nested, hierarchical series of co-evolving structures that emerges from our models of selforganization in complex systems reveals the real links between local and global behaviours. In reality there is no such thing as the "world population", but instead there are many regions, cities and communities and the problems of over-population will strike different parts of the system at different moments. The idea of some forceful action worldwide to reduce the future growth of the world population seems most unlikely, and indeed almost certainly could not be made to work. Conflicting religious, ethnic and social views would seem to make it impossible for anyone to be seen by everyone to act for the good of all. Tragedy elsewhere is an outcome that most people can live with, and so it seems far more likely that disasters will occur, and these may or may not lead to some local action or response to the causes. We should not overlook the possibility of surprises either, as for example, the civilized cradle of protection that antibiotics have provided for 50 years, cracks under the attack of newly evolved resistant strains of bacteria. It is not 
impossible that while the poor world suffers from over-population the rich one might be ravaged by runaway infections. Seeing the world as a selforganizing system does not necessarily offer any simple remedies to these kind of issues. It merely offers a conceptual framework for a better understanding of our predicament, and improved tools with which to imagine possible futures and to respond better than we might have done without them.

Just as for world population, in reality there is no such thing as "the environment", only a set of nested structures which reflect our choice of system boundary. Furthermore, the trajectory or evolutionary path of any particular sub-system is inherently uncertain to some degree, and as a result, even the criteria to evaluate possible actions cannot be established with certainty. But knowing that this is so, is an important step. If we are to learn from the way that the natural world copes with its inability to predict the future, then we see that parallelism, microdiversity and local freedom are key factors in its ability to deal with whatever happens. We must attempt to imitate nature in this respect, and find a system that while evolving enough coherence to function, retains enough individual freedom and microscopic diversity to provide a pool of adaptability and innovation so that it can constantly evolve and restructure in the face of change and can respond intelligently to the challenges and opportunities of the next century.

\section{Acknowledgements}

The urban and regional models were developed with the collaboration of Michele Sanglier, Guy Engelen and Francoise Boon. The three-dimensional visualization was made by Jack Corliss and M. Lesser at the Goddard Space Flight Center, NASA.

\section{References}

"An Integrated Strategic Planning and Policy Framework for Senegal", Under Contract Article 8 946/89 for DG VIII, Rue de la Loi, Brussels 1049, Belgium.
"Agricultural Production and Water Quality in the Argolid Valley, Greece: A Policy Relevant Study in Integrated Method", Archaeomedes Report: 1995, DG XII, Project EV5V-0021, Environment Programme.

"Modelling Phaeocystis Blooms: Their Causes and Consequences." Final Report. DG XII, STEP Programme, Contract CT-0062 (TSTS).

Allen, P.M., 1982, "The genesis of structure in social systems: The paradigm of self-organization", in Theory and Explanation in Archaeology, Ed., C. Renfrew, Academic press, New York.

Allen, P.M., 1984, "Self-organization and evolution in urban systems", in Cities and Regions as Non-linear Decision Systems, AAAS Selected Symposia, 77, Ed., R. Crosby. Westview Press, Boulder Colorado.

Allen, P.M., 1985, "Towards a new synthesis in the modelling of evolving complex systems", in Environment and Planning B, "Planning and Design: Special Issue".

Allen, P.M., 1988, "Evolution: Why the Whole is greater than the sum of its parts", in Ecodynamics, Eds., Wolff, Soeder \& Drepper Springer Verlag, Berlin.

Allen, P.M., 1990, "Why the future is not what it was", Futures, July/August, 555-570.

Allen, P.M., 1992a, "Spatial models of evolutionary systems: subjectivity, learning and ignorance". Chapter 10 in "Spatial Analysis and Population Dynamics", Ed., D. Pumain, Paris J. Wiley-INED, Congress and Colloquia No. 6.

Allen, P.M., 1992b, "Evolutionary theory, policy making \& planning", Journal of Scientific \& Industrial Research, 51, 644-657.

Allen, P.M., 1993, "Evolution: persistant ignorance from continual learning", in "Nonlinear Dynamics \& Evolutionary Economics", Oxford University Press, Chapter III, 8, pp. $101-112$.

Allen, P.M., 1994a, "Evolutionary complex systems: Models of technology change", in "Chaos and Economic Theory", Eds., L. Leydesdorff and P. van den Besselaar, Pinter, London.

Allen, P.M., 1994b, "Coherence, Chaos and Evolution in the Social Context", Futures, 26(6), 583-597, ButterworthHeinemann.

Allen, P.M. and Engelen, G., 1985, "Modelling the spatial evolution of population and employment - The case of the USA", in Lotka-Volterra Approach to Cooperation and Competition Modelling in Dynamic Systems, Eds., W. Ebeling and M. Peschel, Mathematical Research, Academie-Verlag, Berlin, Band 23.

Allen, P.M., Engelen, G. and Sanglier, M., 1983, "Self-organising dynamic models of human systems" in From Microscopic to Macroscopic Order, Ed., Frehland. Synergetics Series, Springer Verlag.

Allen, P.M., Engelen, G. and Sanglier, M., 1986, “Towards a general dynamic model of the spatial evolution of urban and regional systems". In Advances in Urban Systems Modelling, Ed., Hutchinson, Plenum Press.

Allen, P.M. and Lesser, M., 1991, "Evolutionary human systems: Learning, ignorance and subjectivity", in Evolutionary Theories of Economic and Technological Change, Eds., P. Saviotti and J.S. Metcalfe, Harwood Academic Publishers, Chur, Switerland.

Allen, P.M. and Lesser, M., 1993, Evolution: Cognition, Ignorance and Selection. "The evolution of cognitive maps New paradigms for the twenty-first century", The World Futures General Evolution Studies Volume 5, Gordon \& Breach, pp. 119-134. 
Allen, P.M. and Sanglier, M., 1979, "Dynamic model of growth in a central place system", Geographical Analysis, 11(3).

Allen, P.M. and Sanglier, M., 1981, "Urban evolution, self-organization and decision making", Environment and Planning $A$.

Allen, P.M. and McGlade, J.M., 1987, "Evolutionary drive: The effect of microscopic diversity, error making and noise", Foundations of Physics, 17(7), 723-728.

Anderson, P.W., Arrow, K.J. and Pines, D., 1988, Eds. The Economy as a Complex Evolving System, Reading, Addison-Wesley.

Batty, M. and Longley, P., 1994, Fractal Cities, Academic Press, London.

Buza, S., Guerin-Pace, F., Mathian, H., Pumain, D. and Sanders, L., 1995, "Multi-agent systems and the dynamics of a settlement system", Geographical Analysis (to appear).

Clark, N. and Juma, C., 1987, "Long-run Economics - An Evolutionary Approach to Economic Change", Pinter Publishers, London.

Cousins, S., Allen, P.M. and Strathern, M., 1995, Report to the TIGER Project, NERC, Swindon, England.

Eigen, M. and Schuster, P., 1979, The Hypercycle, Springer, Berlin.

Gould, P. and White, R., "Mental Maps", Penguin Books.

Haken, H., 1977, Synergetics, in the Synergetics Series, Springer Verlag, Heidelberg.

Hillier, W. and Hanson, J., 1984, The Social Logic of Space, Cambridge University Press, Cambridge, UK.

Hillier, W. and Penn, A., 1992, "Dense civilisations: the shape of cities in the 21st century", Applied Energy, 43, 41-46.

Hillier, W., Penn, A., Hanson, J., Grajuski, T. and Xu, J., 1993, "Natural Movement: or configuration and attraction in urban pedestrian movement", Environment and Planning B, Planning and Design, 20, 29-66.

Holden, A., 1986, Chaos, Princeton University Press, Princeton New Jersey.
Nelson, R.R and Winter, S.G., 1982, An Evolutionary Theory of Economic Change, Cambridge, The Belknap Press of Harvard University press.

Nicolis, G. and Prigogine, I., 1977, Self-Organization in NonEquilibrium Systems, Wiley Interscience, New York.

Prigogine, I. and Stengers, I., 1987, Order out of Chaos, Bantam Books, New York.

Sanglier, M. and Allen, P.M., 1989, "Evolutionary models of urban systems: an application to the Belgian provinces", Environment and Planning A, 21, 477-498.

Saviotti, P., 1991, "The role of variety in economic and technological development", in Evolutionary Theories of Economic and Technological Change, Eds., P. Saviotti and S. Metcalfe, Harwood, Chur.

Saviotti, P. and Metcalfe, J., 1991, "Present developments and trends in Evolutionary Economics", in Evolutionary Theories of Economic and Technological Change, Eds., P. Saviotti and S. Metcalfe, Harwood, Chur.

Shieve, W. and Allen, P.M., 1982, Self-Organization and Dissipative Structures, University of Texas Press, Austin, USA.

Silverberg, G., Dosi, G. and Orsenigo, L., 1988, "Innovation, diversity and diffusion: A self-organization model", The Economic Journal, 98, 1032-1054.

Weidlich, W. and Haag, G., 1983, Concepts and Models of a Quantitative Sociology, in Volume 14 of the Synergetics Series, Springer Verlag: Berlin, Heidelberg, New York.

White, R. and Engelen, G., 1993a, "Cellular automata and fractal urban form: A cellular modelling approach to the evolution of urban land-use patterns", Environment and Planning A, 25(8), 1175-1199.

White, R. and Engelen, G., 1993b, "Cellular dynamics and GIS: modelling spatial complexity", Geographical Systems, $1(2)$. 


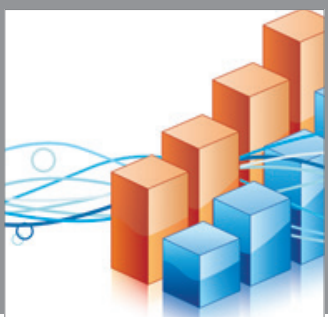

Advances in

Operations Research

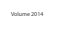

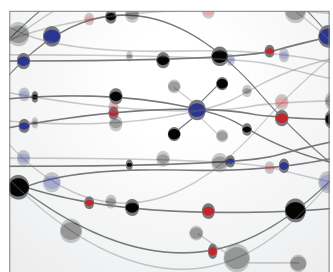

\section{The Scientific} World Journal
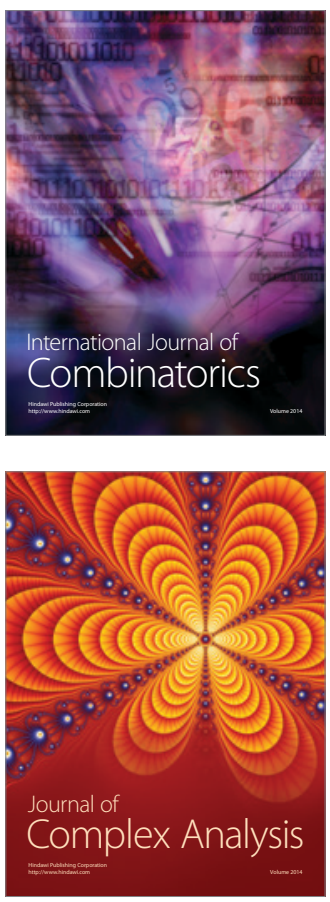

International Journal of

Mathematics and

Mathematical

Sciences
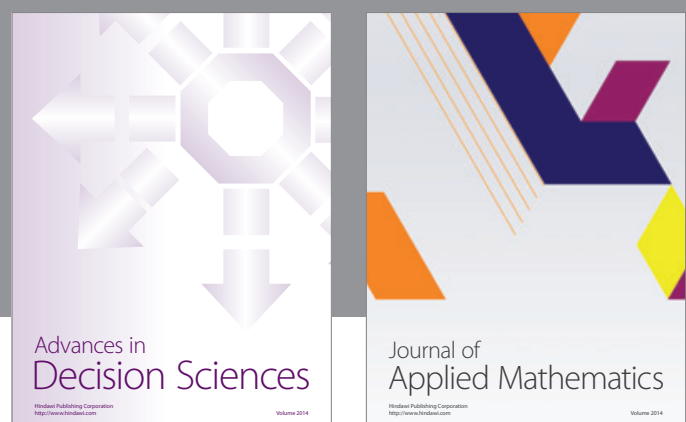

Journal of

Applied Mathematics
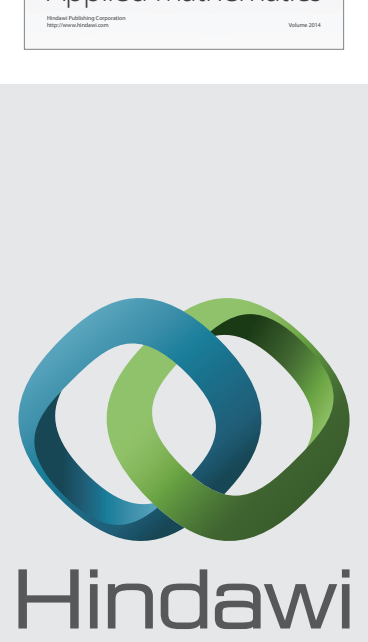

Submit your manuscripts at http://www.hindawi.com
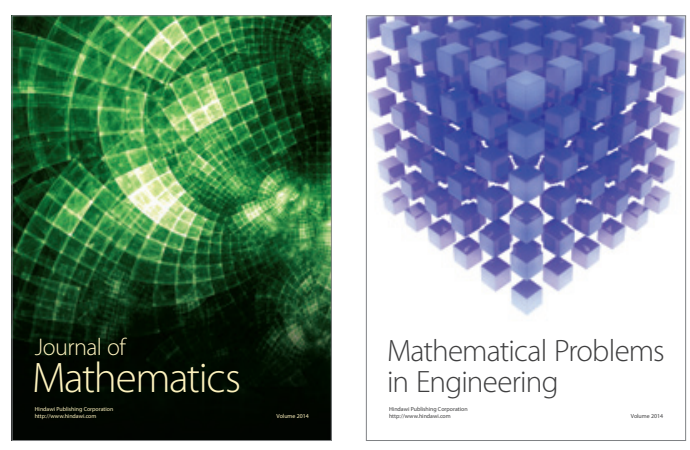

Mathematical Problems in Engineering
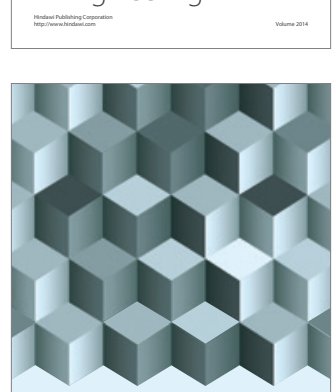

Journal of

Function Spaces
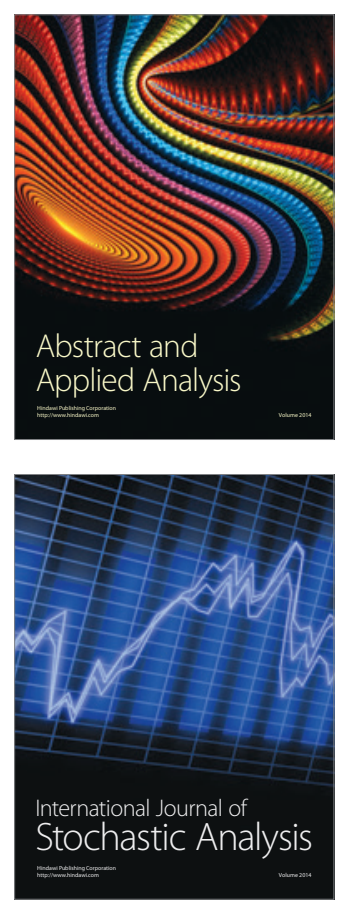

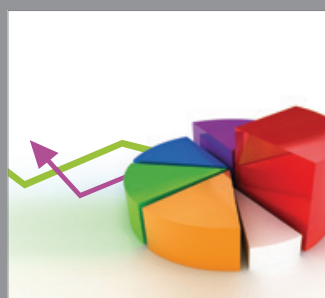

ournal of

Probability and Statistics

Promensencen
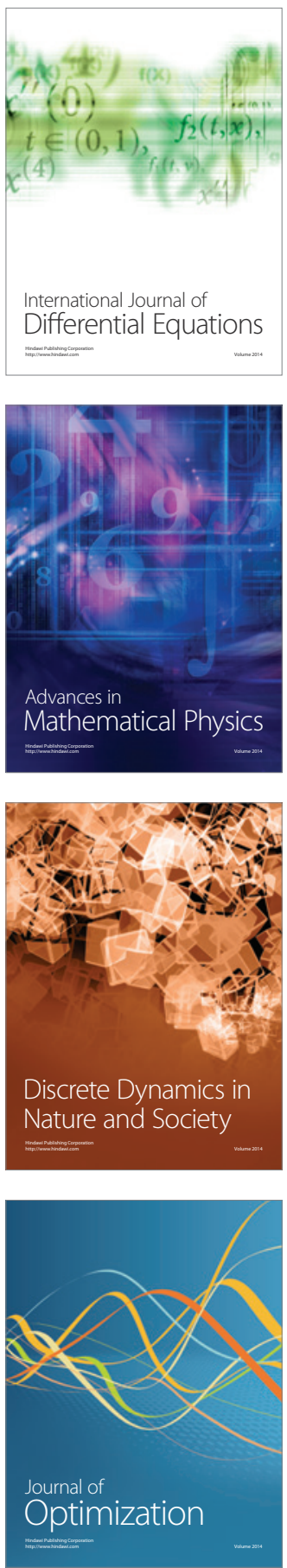